MPAS AND MARINE CITIZEN SCIENCE:

ACCESSIBILITY IN THE MONTEREY BAY NATIONAL

MARINE SANCTUARY

BY

CHRISTINA MARIE HOENOW

A THESIS SUBMITTED IN PARTIAL FULFILLMENT OF THE

REQUIREMENTS FOR THE DEGREE OF

MASTER OF ARTS

IN

MARINE AFFAIRS

UNIVERSITY OF RHODE ISLAND

2020 


\title{
MASTER OF ARTS THESIS
}

OF

\section{CHRISTINA MARIE HOENOW}

\begin{abstract}
APPROVED:
Thesis Committee:

Major Professor AMELIA MOORE

RICHARD BURROUGHS

NORBERT MUNDORF
\end{abstract}

Nasser H. Zawia

DEAN OF THE GRADUATE SCHOOL

UNIVERSITY OF RHODE ISLAND

2020 


\begin{abstract}
The use of marine citizen science in the management of marine protected areas has grown increasingly popular over the past two decades for a variety of reasons. These include increased monitoring and enforcement capacity, increased engagement with the public, and chances for increased social acceptance hopefully leading to more effective conservation overall. California has taken this a step further and included marine citizen science as part of the Marine Life Protection Act (1999) in an effort to increase public access to marine protected areas as well as access to education and information about marine protected areas and conservation in the state. This thesis examines the relationship between marine citizen science, the Marine Life Protection Act, and the environmental and social history of the central coast region of California while attempting to determine if the use of marine citizen science is increasing the equitability and accessibility to the marine protected areas of the central coast region as well as the marine citizen science programs themselves.
\end{abstract}




\section{ACKNOWLEDGMENTS}

My utmost thanks goes to each of the kind members of my committee, Dr. Richard Burroughs and Dr. Norbert Mundorf, for your willingness to help me through this process. I also wish to thank Dr. Graham Forrester for serving as my committee chair and helping to facilitate this daunting process.

I am afraid however, that I do not have the words to appropriately or thoroughly enough express my gratitude to my advisor Dr. Amelia Moore. I have been blessed throughout my academic and professional careers to have incredible female mentors to guide me and help foster my personal and professional growth. Rarely however have I had a mentor who challenged me not only academically but also pushed my personal beliefs and boundaries in a manner which has helped me to hopefully become a more understanding, thoughtful, loving, and accepting person. And she has done this all while making me laugh and feel unconditionally supported along the way while also fostering a loving and enthusiastic "not lab" making the graduate school experience all the more bearable. I am eternally grateful to Dr. Moore for everything she has done for me...particularly for letting me fawn over Bucket the dog who became one of the highlights of my graduate school experience.

My friends and family are too numerous to mention in what I had hoped would be a relatively short and sweet acknowledgements page. However, Dr. Karena Ruggiero and Ryan Nelson, two of my dearest and most supportive friends, have been there for me through every step of this process and I am forever grateful to them.

Finally, I would be remiss to not mention Heather Tallent and Jonas Furberg. Not only have they both created a beautiful community in Blue Planet Scuba where I 
was able to find my true love which ultimately led me to this thesis but they have also been relentless cheerleaders from afar. 


\section{TABLE OF CONTENTS}

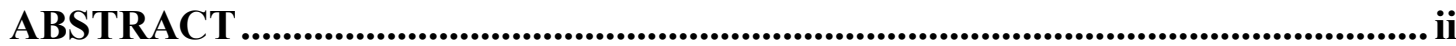

ACKNOWLEDGMENTS ...............................................................................................iii

TABLE OF CONTENTS............................................................................... v

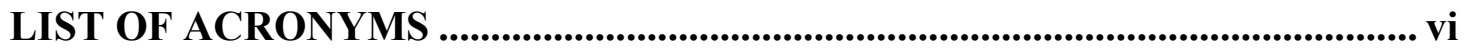

LIST OF FIGURES ........................................................................................................ vii

LIST OF TABLES................................................................

CHAPTER 1 ....................................................................................................................... 1

Citizen Science, Marine Protected Areas, and California: what's it all about?................1

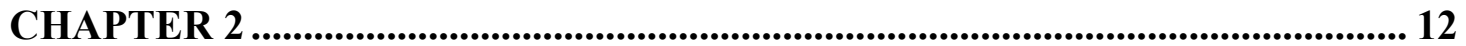

But I'm not a scientist I'm just a normal person! .......................................................12

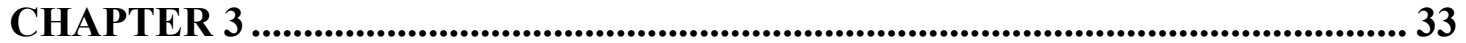

Protected and Marine Citizen Science: what's going on in California?..........................33

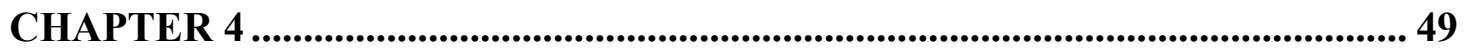

Our History, Their Histories, and Realities....................................49

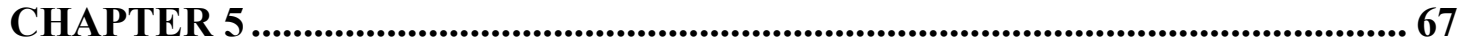

Actions Speak Louder than Well-Intentioned Marine Conservation Policies..........67

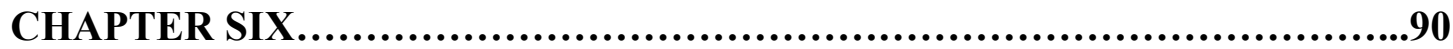

What's it all been about? Final thoughts on MCS, MPAs, and the MBNMS........90

APPENDICES .............................................................................................................96

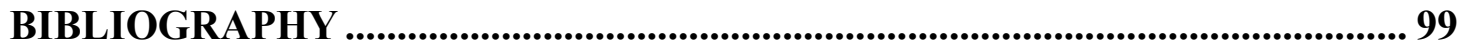




\section{LIST OF ACRONYMS}

$\begin{array}{ll}\text { CA } & \text { California } \\ \text { CCGFRP } & \text { California Collaborative Ground Fish Research Project } \\ \text { CA OPC } & \text { California Ocean Protection Council } \\ \text { CA OST } & \text { California Ocean Science Trust } \\ \text { CDFW } & \text { California Department of Fish and Wildlife } \\ \text { CLSC } & \text { Chautauqua Literary and Scientific Circle } \\ \text { CS } & \text { Citizen Science } \\ \text { EEZ } & \text { Exclusive Economic Zone } \\ \text { LiMPETS } & \text { Long-term Monitoring Program and Experiential Training for } \\ & \text { Students } \\ \text { MBA } & \text { Monterey Bay Aquarium } \\ \text { MLPA } & \text { Marine Life Protection Act } \\ \text { MPA } & \text { Marine Protected Area } \\ \text { SMR } & \text { State Marine Reserve } \\ \text { SMCA } & \text { State Marine Conservation Area } \\ \text { MBNMS } & \text { Monterey Bay National Marine Sanctuary } \\ \text { MCS } & \text { Marine Citizen Science } \\ \text { NOAA } & \text { National Oceanographic and Atmospheric Administration } \\ \text { RCCA } & \text { Reef Check California }\end{array}$




\section{LIST OF FIGURES}

FIGURE

PAGE

Figure 1. Overlay map of the MBNMS with all of the California state MPAs...........3

Figure 2. NOAA MBNMS Office in Monterey....................................4

Figure 3. Map of MPA Watch survey route..................................27

Figure 4. MPA Watch survey sheet........................................27

Figure 5. Harbor seal colony on Point Cabrillo beach ...........................28

Figure 6. Hopkins Marine Station Laboratory................................. 29

Figure 7. Placard denoting the Monterey Peninsula's MPAs........................34

Figure 8. Sign denoting a no-take state marine reserve......................... 36

Figure 9. Map of the California MPA network.................................. 37

Figure 10. MBNMS Facebook Post......................................44

Figure 11. Informational Flyer printed by David.............................47

Figure 12. Lettuce fields in Monterey County................................52

Figure 13. Placard outside of the Hopkins Marine Station........................57

Figure 14. "Lettuce Curtain" ...........................................64 


\section{LIST OF TABLES}

TABLE

PAGE

Table 1. MCS programs discussed in this thesis............................... 9

Table 2. MCS Data Accessibility ............................................... 16

Table 3. Replicable qualities of successful MCS programs.......................93 


\section{CHAPTER 1}

\section{Citizen Science, Marine Protected Areas, and California: what's it all about?}

In the summer of 2019, I attended a workshop hosted by the California Marine Protected Area (MPA) Collaborative Network. This workshop addressed the current state of MPA public engagement and outreach efforts spanning California's MPA network . Throughout the workshop there were a series of 45- minute breakout sessions which focused on different engagement methods and practices. These included social media use, education, youth programs, indigenous communities, recreational and commercial fishing, and of most importance for this discussion, citizen science (CS). I was already familiar with a number of the participants in the CS breakout discussion, having interviewed them earlier in the summer as part of my research, but I was curious what direction the conversation would take since I had come across such a variety of opinions regarding CS during my interviews. I was not shocked when the initial attempt to define citizen science in the context of the California MPA network rapidly devolved into a back and forth spat over whether these programs should be called citizen or community science. Ultimately, this debate took nearly half of the 45-minute session before the group leader, Rachel, an individual who is a pillar in the citizen science community of Central California, as well as one of the individuals I interviewed for this project, David, stepped in and shut the debate down. The citizen versus community problem is one I have become very familiar with throughout my data gathering and permeates and demarcates the different organizations and approaches to citizen science found in this space. I found that within the central coast community, referring to citizen science programs as 
"community science" is a first step of sorts to attempt to increase the inclusion, equitability, and accessibility of citizen science programs. However, I believe that while this is a positive recognition that steps should be taken to increase the accessibility and equitability of citizen science programs, it is actually a misapplication and co-opting of the term. Additionally, I believe the use of the term community science in place of citizen science is being used as a band-aid solution instead of actual concrete and measurable changes being implemented to increase the equitability and accessibility of California's marine citizen science (MCS) programs and MPAs.

This debate highlights another issue which challenges marine conservation practitioners, managers, and participants. No one agrees on what exactly these citizen science programs are supposed to be doing. The Marine Life Protection Act (MLPA) introduced MCS as a legally mandated form of public engagement with MPAs in California in an effort to increase the equitability and accessibility of marine conservation policy in the state. As a result, dozens of MCS programs have popped up along the coast with little oversight or guidance from the state as to how they should operate and what their goals are. These programs vary in type, method, as well as the forms and amounts of data they produce. To date however, there has been a distinct lack of specifics or clarity from legislators and authors of the MLPA in Sacramento to guide these programs as they enter their second decade of operation on the central coast of California.

By extension, the question of what exactly these MCS programs are supposed to be doing can be further developed to include other questions like should specific 
programs prioritize data collection over engagement? Or should engagement with as many parts of the regional community be the priority over data collection? How engaged with participants should these programs be and what counts as engagement? What role does education and outreach play in citizen science? Through numerous interviews, participant observation, and literature review I have identified a number of

Figure 1: Overlay of the MBNMS with CA MPAS, NOAA

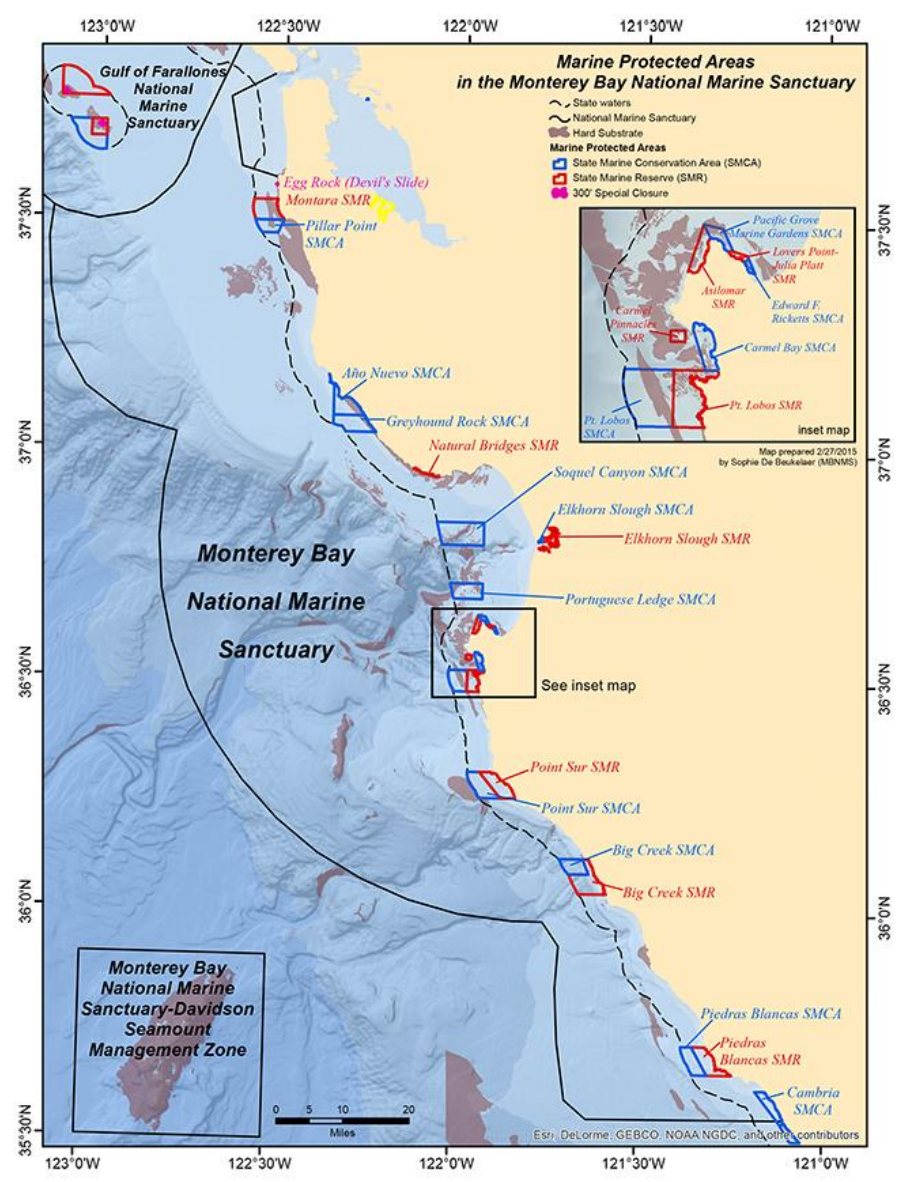

factors which contribute to the uncertain purpose and practice of MCS programs in California. These include the Marine Life Protection Act and the practice of MPA management, the presence of external non-state based entities like the National Oceanographic and Atmospheric Administration (NOAA), and the social and environmental histories of the communities which dot the coast of the Monterey Bay National Marine Sanctuary (MBNMS; Figure 1).

In order to answer these questions, I decided it would be best to spend time on the ground in the various coastal towns and cities found along the central coast of California. I ended up spending June, July, and August of 2019 visiting many of these towns including Monterey, Santa Cruz, San Francisco, Pacific Grove, Seaside, and 
Salinas. I also spent

time in the NOAA

offices, located about

a minutes-walk away

from the beach in

Monterey (Figure 2),

getting to know the

MBNMS staff and

programs as well as

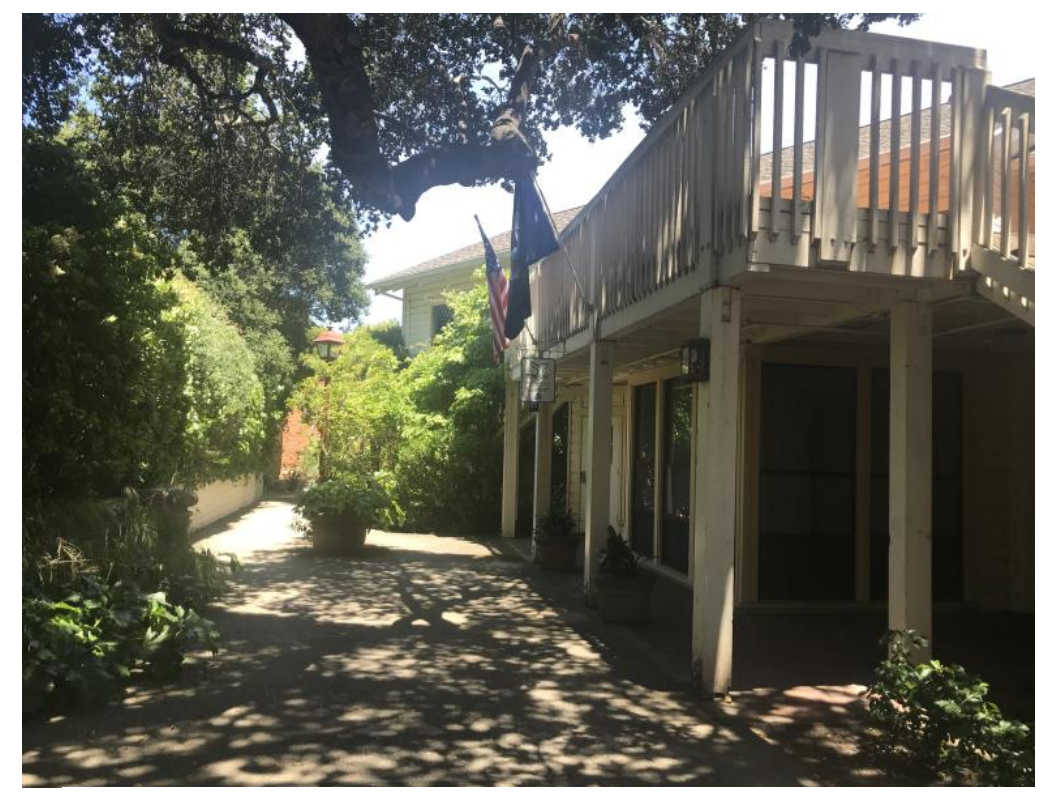

Figure 2: MBNMS NOAA offices in Monterey, Authors personal photos

the MBNMS itself. As I got to know the individuals I interviewed for this thesis during those three months I also attended a number of events about MPAs and public engagement with California's MPA network. Additionally, I participated in and observed a number of MCS programs discussed throughout this thesis. Since the MLPA was enacted in the central coast region in 2007, these MCS programs are still relatively new and under studied on a broad level; something I discerned from my exhaustive literature review as well as conversations with academics involved in the implementation and development of the MLPA. Because of this I chose to use semistructured interviews, participant observation, and document review to help me understand what exactly is happening with the numerous MCS programs which have appeared throughout the region. I settled upon an overarching research question to get a general sense of the understanding of MCS, what its perceived role is, and what factors, if any, are allowing these programs to increase the equitability and accessibility of California's MPA network. Therefore, the overarching question which 
shaped this thesis is "How is MCS defined by those involved in this region and is it being used to increase the accessibility and equitability of California's MPA network?" Additionally, I developed three sub questions as well: 1) What role has the MLPA played in creating an environment conducive to impactful community engagement with MPAs through MCS? 2) Are MCS programs operating in the MBNMS accessible to all potentially interested parts of the community? 3) What role does the environmental and social history of the central coast region have on the proliferation and functioning of MCS programs there?

\section{Methods}

In developing this thesis I considered a number of qualitative and quantitative methods including surveys, semi-structured interviews, participant observation, document review, and unstructured interviews. I ultimately decided to use qualitative methods including semi-structured interviews, participant observation, and document review due to the nature of the subject matter this thesis explores and as well as desire for this thesis to be relatively exploratory rather than explanatory (Johnson and Hruschka 2015). While there is a comparatively large body of research addressing the MLPA and MCS, the research body addressing MCS within the context of the MLPA is much smaller since MCS has been in use in this context for a relatively short time. According to Johnson and Hruschka, qualitative and exploratory inquiry is crucial for later theoretical analysis and more targeted research development $(2015$ p. 107, 108). Based off of these factors, and the ethnographic research recommendations of 
Barnard, Johnson, and Hruschka, I settled upon using a qualitative exploratory research design for this thesis (2015).

I chose three methods of data collection: semi-structured interviews, participant observation, and document review. I chose these methods specifically as a means to ensure the reliability and soundness of the conclusions I draw in this thesis. The use of three methods of data collection allowed for triangulation and identification of themes across multiple sources (Cresswell 2014), thereby ensuring that each conclusion I drew in this study would stem from multiple points of source data.

I chose semi-structured interviews in order to allow for flexible and organic conversations to occur between myself and each of the individuals I chose to interview. I developed a set of specific questions addressing age, job, racial identification, languages spoken, city of residence, and personal definitions of MCS and MPAs which I asked each individual I interviewed. After asking each individual the questions mentioned above I then was able to facilitate natural conversation, situated listening, and direct and precise questions appropriate to each specific individual as described by Barnard and Spencer (2009). I used the method of probing as described by Robson and McCartan to encourage elaboration by each individual I interviewed on specific topics most relevant to them (2016). For example, in interviews with MCS program managers I emphasized questions regarding steps they are taking in the design of the MCS programs they run to reach a broader participatory audience including multilingual tools, geographical distribution, and bottom up program design. 
As one of the goals of my study was to understand the on the ground practices of MCS programs within the boundaries of the MBNMS, connecting the dots of intention and actions, participant observation was a notably useful tool in my data collection methodology. I not only participated in specific MCS activities like MPA Watch Surveys, I also attended a California MPA Collaborative workshop which was attended by a number of my interview subjects which focused on the role of public engagement and outreach for the California MPA system in which MCS played a prominent role. These instances of participant observation were extremely enlightening; particularly as the first instances of observation I participated in occurred extremely early in my data collection, and the workshop I attended and observed was near the end of my data collection period.

I documented my participant observation experiences through written field notes and informal observations (Barnard and Spencer 2009). Observations from these field notes were then used to triangulate themes I identified during interviews and helped me come to the conclusions discussed in this thesis .

I chose snowball sampling as my means of identifying potential interview subjects. This was based on early conversations I had with MCS program managers and participants prior to the formal start of this study. I got a sense at the beginning of this project's formulation that these programs in the Monterey Bay area were made up of active and engaged individuals who make a generally concerted effort to collaborate and engage with local communities. As a result, people know who the other relevant people are and it is not a particularly large community of practitioners or participants. I identified 10 individuals initially through literature review and web searches. These 
individuals included academics, policy makers, MCS program directors, and MBNMS sanctuary staff. Following the completion of my interviews with each of these initial 10 interview subjects I asked each of them to provide me with the contact information of anyone else they felt would be potentially helpful or interested in participating in my study. Through this method I ultimately conducted 16 interviews with the following breakdown in interview subjects: 3 academics, 2 MBNMS staff members, 4 non-profit MCS program directors, 2 boundary organization representatives, 2 NOAA program managers, 1 NOAA Sanctuary Advisory Council Member, and 2 MCS participants. One specific article (Meyer et al., 2017) provided a critical discussion of the initial five years of marine citizen science on the central coast of California and served as a point of initial identification for a number of these individuals.

Each of the individuals I chose to interview had been involved with citizen science in the Monterey Bay National Marine Sanctuary since 2007, save one participant and one program manager who were both recent transplants to the area. However, this mix of individuals drew from a wide breadth of experience including NOAA sanctuary staff, California state policy makers, academics, MCS program managers, MCS participants, and the director of a boundary organization involved in the formulation and implementation of the MLPA. As this study is the first of its kind evaluating marine citizen science programs in this region, limiting my interviews to relatively accessible individuals who are the face of their respective programs or roles was a prudent decision in shaping my research.

The central coast of California is a veritable hotbed of MCS programs. These programs vary in size, scope, purpose and accessibility. Additionally, the numerous 
programs are housed and hosted by a variety of organizations including research institutions, government bodies, and non-profits. The following MCS organizations listed in table 1exist and operate within the geographical space encompassed by this study, although this list is not exhaustive.

\begin{tabular}{|c|c|}
\hline Program & Activity \\
\hline LiMPETS & Shore and intertidal based surveys; documenting sand crabs and tidal life \\
\hline Reef Check California & $\begin{array}{l}\text { Scuba diving; rigorously designed marine life surveys using scientific } \\
\text { collection methods }\end{array}$ \\
\hline Snapshot Cal Coast & Shore/water based; 24 hour state wide event documenting marine life \\
\hline Bay Net & $\begin{array}{l}\text { Shore based; naturalist docents teaching the public about marine } \\
\text { mammals }\end{array}$ \\
\hline INaturalist & Shore/water based; photo identification of terrestrial or marine life \\
\hline MPA Watch & Shore/water based; surveys of recreational activity and marine life \\
\hline BeachCOMBERS & Shore based; seabird mortality surveys \\
\hline Team Ocean & Water based; naturalist docent program, sister program to Bay Net \\
\hline First Flush & $\begin{array}{l}\text { Shore based water quality sampling of storm drain output during the first } \\
\text { seasonal rains }\end{array}$ \\
\hline Watershed Watch & Shore based; water shed water quality monitoring \\
\hline Plankton Monitoring & Water based; plankton collection and sampling \\
\hline Project Aware & Scuba diving; Debris removal underwater and documentation \\
\hline REEF & Roving scuba diver surveys; fish species counts \\
\hline $\begin{array}{l}\text { California King Tides } \\
\text { Initiative }\end{array}$ & Shore based identification of king tides \\
\hline $\begin{array}{l}\text { California Collaborative } \\
\text { Groundfish Project }\end{array}$ & Boat/shore based; groundfish surveys \\
\hline
\end{tabular}

Table 1: MCS programs on the central coast of California

A number of factors contributed to the programs I selected for data collection for this study. Accessibility and access were two key factors. If I was unable to make reliable contact with any individual representatives or participants by mid-September then I chose to not pursue that program any further for the sake of time and maximizing my potential data collection. As I conducted my research over the course of the summer I additionally concluded that in order to prevent the amount of data collected from becoming unmanageable, limiting the number of programs I considered through both interviews and participant observation would be a realistic choice. 
The confidentiality and security of each of the individuals with whom I spoke is of the utmost priority for me. Therefore, all names used throughout this thesis are pseudonyms. Additionally, I have also used different names for institutions where many of these individuals work or study so as to protect their confidentiality. However, as the MCS community throughout California as a whole is relatively well connected, many of the individuals I interviewed were familiar with each other and referenced each other during our conversations. In instances where someone I was interviewing referred to someone else I had interviewed by name, I use the pseudonyms I chose for this study in place of their actual names in any quotes or discussion of those interviews.

The chapters of this thesis are a thorough examination of the context which helped me to shape my research questions and created the current environment in which these MCS programs operate and of the findings from my interviews. In chapter two I introduce both CS and MCS, discuss some of the things I learned about the MCS programs in the region, share some of my personal reflections on a participant observation experience, and conclude with a definition of MCS which I derived from my interviews and experiences. Chapter three includes an overview of MPAs, the MLPA, the MBNMS, and the role played by MCS programs in California's MPAs as well as MPAs around the world. Chapter four is an examination of the social and environmental history which helped to create the uniquely environmentally conscious space that is the central coast region and how this history has created a situation in which exclusion and erasure from the ocean and coast must be reckoned with today in order to both meet the goals of the MLPA and to create a more effective approach to 
marine conservation. Chapter five is the major discussion of my findings including the four conclusions I came to after considering all of my collected data, personal observations and experiences, background research discussed in the previous chapters, and reflect my four research questions. My four conclusions are: 1) that context and historical realities have created an "imagined public" which must be acknowledged and reckoned with in California, 2) the lack of specific guidance from the MLPA regarding what exactly the role of MCS is contributes to the continued inequity and inaccessibility of both MCS programs and MPAs, 3) MCS programs in the region are in fact taking positive steps to both increase equitability and accessibility but also to better the state's overall approach to marine conservation and, 4) NOAA's presence and role in the region is a complicating factor which is contributing to perceptions that MPAs and MCS are exclusionary and inaccessible and increase distrust in both California's marine conservation approach and MCS programs. 


\section{CHAPTER 2}

\section{But I'm not a scientist I'm just a normal person!}

I began this thesis knowing I would need to determine what each individual I interviewed defined citizen science and marine citizen science as. So, I chose to begin each of the sixteen interviews I conducted with the question "how do you define citizen science?" Starting with this question allowed me as the interviewer to initially identify specific topics that I deemed noteworthy and felt should be discussed, or "probed" further. My answer to this question, which I discuss at the end of this chapter, also let me answer part of my overarching research question "how do these people define marine citizen science". Additionally, it allowed me to gain insight into many of the challenges facing the MCS community on the central coast of California.

While there is no singular definition of citizen science (CS) it is commonly agreed upon as being "public participation in organized research efforts by private citizens who have chosen to use their free time to engage in scientific processes" (Dickinson and Bonney 2012 p. 1). This definition highlights three critical aspects of the citizen science definition: private citizens, free time, and scientific processes. "Private citizens", or the people who are participating in citizen science programs, are the key to citizen science. Their labor is supposed to increase the capacity of scientists and environmental managers and their participation also can enhance both science and environmental research. However, who these people, with their "free time", are and whether or not they are representative of the communities they live in in is an ongoing struggle for many CS program managers around the world. Finally, while Dickinson and Bonney have created a relatively straightforward definition some scholars feel it 
does not accurately represent the breadth of citizen science and the many roles it can play or the importance of engaging diverse populations (Pandaya 2012; Silvertown 2009).

Marine citizen science (MCS) now plays an extremely important role in California's approach to MPA management (Cigliano et al., 2015; Friewald et al., 2018). Its recognition as a tool to marine management capacity as well as a tool to increase both the equitability and accessibility of California's MPAs is a novel approach (Baird and Mace 2006). However, while Marine Life Protection Act (MLPA) is a groundbreaking measure it does not include any specific guidelines or even definitions of what MCS is or what exactly it is supposed to be doing often leading to competing or conflicting goals.

While conducting the interviews for this thesis I realized many of the individuals I spoke with had varying understandings and definitions of citizen science. I also discovered that scientific data produced through MCS, despite the growing body of literature touting its reliability, is still regularly questioned and doubted by both scientists and practitioners (Cohn 2008; Bonney et al., 2009; Gillet et al., 2012; Moritsch 2018). As a result of this I believe that a thorough discussion of what exactly CS and MCS are, particularly the programs which exist on the central coast of California is important to the overall soundness of this thesis. The following section will discuss many of the different facets of citizen science including: what marine citizen science can look like in practice, why it has become so popular, the difference between community and citizen science, the question of accessibility and equitability within citizen science programs, and a brief reflection on my personal experience with 
MCS in the Monterey Bay National Marine Sanctuary while conducting this research. Finally, this section will culminate with my own adapted definition of citizen science which will be used throughout the rest of this study that is based upon my analysis of the response to the question "how do you define citizen science?" which I asked each person that I interviewed.

\section{What is marine citizen science?}

Citizen science, as a tool used for environmental management and ecological monitoring, has increased in popularity immensely in recent decades (Dickinson and Bonney 2012; Caitlin-Groves 2012). Turrini et al., specifically identified three components which have led to the increase in number of citizen science projects used for environmental management. The first being that "it provides opportunities to generate knowledge and insights which are new for and relevant to science, society or administration and management, especially with respect to nature conservation" (Turrini et al. 2018 p. 176) Second, it allows participants to increase their scientific and environmental literacy as well as gain exposure to the scientific process and methods (Turrini et al. 2018 p. 176) Third, citizen science can allow for empowering citizens by providing scope for civic participating and involving people in policyrelevant debates and decision-making processes" (Turrini et al. 2018 p. 177).

Citizen science has exploded into the public realm over the last three decades. What started initially as small, localized projects in the 1980's has grown into thousands of major internationally coordinated research efforts around the globe. Early citizen science programs included a localized bird monitoring project called 
"NestWatch" hosted by Cornell University’s Ornithology Lab (Bonney and Dickinson 2012). More recently citizen science has proliferated beyond the terrestrial and into the world's oceans with programs like Reef Check, REEF, LiMPETS, INaturalist, MPA Watch, and Team Ocean (Thiel et al., 2104). These MCS programs can now be found all across the world with seagrass monitoring and planting with Project SeaGrass Grow in the United Kingdom, coral reef monitoring in Jamaica through the EarthWatch Institute, invasive lionfish removal and tracking in the western Atlantic, and vertebrate and invertebrate marine life surveys conducted around the world through Reef Check (Jones et al., 2017; Crabbe 2012; Malpica-Cruz, Chaves, and Côte 2016 ;Friewald et al., 2018).

These MCS programs vary immensely in terms of the amount of training, tools, quality and accessibility of produced data and resources needed to participate in them. Programs like Reef Check California require participants to have advanced scuba training, a large number of recreational dives documented in the area where Reef Check survey's will be conducted, an intensive training in conducting underwater surveys and species identification in a confined water setting, then multiple "check out" dives in the open water under supervision, and annual recertification (Reef Check California Website accessed February 2020). Whereas programs like INaturalist and MPA Watch can be conducted from the shoreline and require little more than a brief overview of the survey sheet and are accessible to almost anyone who wants to participate, and the data is simply uploaded to an online portal. An increasingly popular aspect of many of the MCS programs which operate on the central coast of California is the accessibility of the data produced. Many of the 
MCS participants I interviewed identified the ability to see the data they helped to produce and see how it is being used would make their MCS participant experience even better. Despite this growing mindset a number of programs like Reef Check, notably those programs which most closely resemble traditional academic research, still use a traditional closed access model of data maintenance (Table 2).

\begin{tabular}{ll}
\hline Open-Access Data & Closed-Access Data \\
\hline LiMPETS, REEF, Snapshot Cal Coast, & Reef Check California, California \\
MPA Watch, Project Aware, INaturalist, & Collaborative Groundfish Project, \\
First Flush, Watershed Watch, Team & California King Tides Initiative, \\
OCEAN, Baynet & Plankton Science Monitoring Network, \\
& BeachCOMBERS
\end{tabular}

Table 2: MCS Data Access

Underwater exploration, monitoring, and research has long been a challenge for MPA management due to lack of capacity; after all, humans are not marine mammals. Which in turn can often lead to poorly run and ineffective MPAs (Gill et al., 2017). When coordinating research and monitoring programs for terrestrial spaces capacity is often less of a concern as there are little to no extra skills or training needed to access the space to be examined. Whereas, MPA management and marine research pose extensive logistical and accessibility challenges due to the simple fact that the ocean is not as easily accessed as the land is.

This is where MCS comes in! Marine citizen science often benefits from highly motivated groups of willing volunteers with specific aquatic skills and access including scuba divers, snorkelers, surfers, and boaters (Thiel et al., 2014). As a dive instructor and active marine citizen scientist I can personally attest that I am highly invested and motivated to help out where I can if it will help promote effective marine conservation. The high levels of motivation to participate shown by MCS volunteers 
has created a willing and ready body of volunteers who could help easily fill many of the capacity gap MPA managers are facing around the world (Schläppy et al., 2017; Banchini et al., 2015; Lucrezi et al., 2018; Cigliano and Ballard 2017). As capacity issues in MPA management are increasingly recognized as major gaps in environmental management scholars and protected area management around the world are recognizing the usefulness of MCS as a highly beneficial tool (Aceves-Bueno 2015).

\section{Is there a difference between terrestrial citizen science and marine citizen science?}

MCS is citizen science which takes place in or immediately adjacent to the marine environment (Thiel et al., 2014; Cigliano et al., 2015; Cigliano and Ballard 2017; Dickinson and Bonney 2012). MCS differs from terrestrial citizen science in a number of ways including logistical challenges, access, and specialized skills as referenced in the previous section (Cigliano et al., 2015; Cigliano and Ballard 2017; Thiel et al., 2014). Many of these challenges can be overcome by enlisting the help of boaters, divers, and fishermen as well as coastal residents familiar with the marine environment (Cigliano and Ballard 2017). Involving individuals such as fishermen can increase logistical success as well as provide MPA managers access to local ecological knowledge which could otherwise be ignored (Cigliano and Ballard 2017; Lauer and Aswani 2009). However, scholars note that social challenges such as prejudice against perceived "extractive" users of the marine environment can inhibit MCS program 
managers from seeking out these individuals (Vann-Sander, Clifton, and Harvey 2015).

Early on in designing this thesis I stumbled upon a study authored by the California Ocean Protection Council and California Marine Sanctuary Foundation in September 2018. This report identified five key gaps in MPA education and outreach in central California. One of the key gaps identified was in engagement with fishermen. The report stated, "the recreational fishing community remains an underserved audience and potentially powerful ally in need of targeted MPA outreach" (CA OPC 2018 p. 14). This finding stood out to me for a variety of reasons. One being that the inclusion of fishermen in planning, management, and enforcement of MPAs often results in more successful marine conservation (Helvey 2004). Additionally, many fishermen, including the extremely successful rock lobster fishery of southern California, were actively engaged in MCS programs during the first five-year monitoring period of the MLPA (Morin Dalton 2005; Stern 2008; Meyer et al. 2017). I attempted to discern why fishermen have been ignored on the central coast and left out of the MCS and MLPA processes here when they are regularly identified as being highly important.

The responses I got to my questions of "Do you know of any MCS programs which specifically target fishermen" and "Where do the recreational fishermen fit into this process" highlighted this gap but didn't exactly help me narrow in on why fishermen are ignored. Robert, an academic I interviewed, responded to my question of "where are all the fishermen" by highlighting an active program being led by an 
individual in Los Angles who collects fish biomass data from both shore and off-shore recreational fishermen. However, when I asked him if he knew of anything similar on the central coast he shrugged and responded "your guess is as good as mine!" Angela, a director of citizen science at a large public facing science institution in San Francisco, shared with me that lingering resentment within the recreational fishing community at the MLPA has impacted efforts to engage them in MCS programs. Though increasingly, Angela shared, fishermen are interested in offering information on fish biomass based on their catches from areas which are not necessarily relevant to MPA management. This misalignment often results in prickly exchanges between scientists, California Department of Fish and Wildlife Wardens and the fishermen themselves according to Angela.

The logistical, skill, and access challenges often created by marine citizen science discussed above have created an environment around marine citizen science where scuba divers have historically been the most involved and most actively engaged participants. Studies done by Cerrano et al (2017), Martin et al (2017), and Lucrezi et al (2017) have identified professional scuba divers (those holding the professional level certification of divemaster or above) as being the most likely marine citizen science participants. This tendency towards marine citizen science participants being relatively privileged and already well-educated raises questions about the potential capacity for citizen science programs to reach community members outside of this relatively small bubble. 
A number of the interviews I conducted highlighted the fact that the more exclusive forms of MCS like Reef Check California, which depend upon highly trained recreation divers, are often privileged over other more accessible programs. This all happening despite the increasing understanding that the majority of data produced by MCS is both sound and useful in some capacity. Robert spared no detail when sharing his opinions about the "exclusive" nature of Reef Check California and its seeming monopoly over much of the state funding for MCS programs. He also shared with me that the continued preferential treatment of programs like Reef Check California, which have a twenty-year history of partnering with academic and state environmental research laboratories, is viewed as a "knee jerk" reaction from state and private funding bodies. Robert's stated, "so of course Reef Check gets funded 'cause they look the most like an academic research arm ... and they all decided to go with what's comfortable and what they know." Robert attributed this reaction to a lack of understanding of what exactly these newer, more accessible MCS programs are supposed to be doing and what impact involving less intensively trained programs into the MCS inner circle will have, so to speak.

Citizen science has been found to not only shape research agendas to reflect environmental needs more accurately than individual research interests alone but to also "be more responsive to broad social concerns" rather than just the research and monitoring interests of academics and scientists (Ottinger 2010). Using multiple forms of MCS to help inform MPA management in California has the potential to help overcome the challenges Robert shared with me. This point in particular has helped me to shape this study because the intention of including citizen science in the MLPA 
was not only to increase monitoring capacity but also to increase inclusion and equitability in the MPA management process. It would seem to make sense then that the goals of these marine citizen science programs included the intended purpose of running as equitably and accessibly as possible. However, based off of the initial research I completed when developing this project it does not appear that this is the case.

Marine citizen science has been recognized by a number of MPA scholars as a tool through which diversity, accessibility, and equitability in MPA management can potentially be increased (Meyer et al., 2017; Aceves-Bueno et al., 2015; Hyder et al., 2015; McKinley et al., 2015; McKinley et al., 2017; Thiel et al., 2014). However, the inclusion of historically marginalized groups requires concrete effort from MPA managers and MCS program staff (Meyer et al., 2017). While recognized for its potential to increase access to MPAs MCS has also been described as "stamp collecting of social capital for wealthy, white, interested people" (Cigliano and Ballard 2017; Bonney et al., 2009; Dawson 2014, 2018). As will be discussed in Chapter 4, I hypothesize that the unique social and environmental history of the central coast region has in fact created a "stamp collecting" situation like the one Cigliano and Ballard warned against.

This phenomenon is unfortunately highly under studied. According to Hermosa et al., "evidence suggests the people most interested in CS programs are those already concerned about science and the environment meaning that CS will naturally attract a particular type of participant (pro-science or pro-environmental) 
rather than a broad reach across audiences with many different science/environmental attitudes" (2019 p. 2). The concern that the only people involved in marine citizen science in the Monterey Bay National Marine Sanctuary (MBNMS) are of a particular type (wealthy, privileged, and white) who are seeking to participate in these programs for social capital and to prop up their status within the community is a logical one. Further, this concern is particularly justified when one takes into consideration the environmental and social histories of the region which will be discussed extensively in Chapter four.

\section{Citizen vs. Community science}

The anecdote I opened this thesis with highlights a point of importance in this study. Approximately half of the individuals I interviewed who represented both local non-profit organizations, federal governing bodies, and individual marine citizen science participants emphasized to me the importance of calling marine citizen science programs "community science" instead of "citizen science". It became quickly apparent to me through probing during these interviews that the preference for "community science" instead of "citizen science" stemmed from a desire to promote inclusion. However, my analysis has led me to conclude that this is ultimately an unfortunate misapplication which may ultimately do more harm than good.

Community science is a term which has been used in the context of environmental justice, community health, and community organization as opposed to usage in environmental research and monitoring. Abraham Wandersman defines community science as "an interdisciplinary field, which develops and researches 
community-centered models that enable communities to use evidence-based interventions more effectively and efficiently" (2003 p. 236).Community science is an epistemologically new term as well as classification of community-based science. However, as recognition of community science as a valuable tool for communities as well as academics and civic organizations questions have arisen regarding what exactly "community science" is. According to Wandersman and Cates a key part of community science is that it acts as "preventative science," or monitoring and tracking of shifts in the environment which could pose a potential threat to communities, which creates a whole of preventative knowledge greater than the sum of its component parts (2003; 1995). The emphasis on "preventative science" as a critical attribute of community science differentiates it from Citizen science. Additionally, community science is formally defined by Wandersman as:

science to improve the quality of life in our communities by improving the quality of the practice of treatment, prevention, health promotion, and education. Community science develops and researches community-centered models that enable communities to use evidencebased interventions more effectively and efficiently. Community centered models embrace a science of community that includes (1) community influences on individual, family, and other subsystems; (2) the influence of individuals, families, and other systems on the structure and functioning of community systems (e.g. citizen participation, community mobilization, school improvement councils, voting); and (3) power, influence, and policy (e.g. sociological and 
political science models of power). Community science is

multidisciplinary, interdisciplinary, and transdisciplinary—drawing upon anthropology, biomedical sciences, education, political science, biomedical sciences, education, political science, psychology, prevention science, public health, social work, sociology, and related fields. (Wandersman 2003 p. 3)

Community science is therefore a tool intended to be used by communities, to be fostered within said specific places, by residents of said community. It is something which is supposed to give communities agency over their well-being and act as a tool from which they can invite external bodies in to help with threats to public health and environmental justice issues. It is intended to be a bottom up, collaborative, and user driven process which differs from a majority of the marine citizen science programs which operate within the MBNMS despite the popularity of collaborative and user driven citizen science programs.

Throughout my interviews, a number of opinions came up regarding the usage of community science as the identifying term instead of citizen science. These range from extremely positive and hopeful to negative and mistrustful of the application of this term. David, one of the individuals who was involved in the opening anecdote, has a particularly strong opinion on this issue. He shared a story with me during our interview which showcases how using the term community science is viewed in some circles as an excellent tool for increasing the perceived equitability and access of these programs to participants from outside of the traditional wealthy, white, and privileged individuals. David's story takes place at a local marine citizen science training 
meeting in Pacific Grove, California. He told me that at this meeting a few years ago a young boy, who he identified as being Latino, raised his hand and asked "But if I am not a citizen, can I still participate in citizen science?" While I question the details of this story, as David is an individual prone to flair and enthusiasm of the sort which often leads to embellishment, it emphasizes a critical point in the citizen science vs. community science debate; language matters. In the current political climate, particularly that which exists in the relatively left leaning central coast of California, the current administration's aggressive and hurtful actions towards undocumented people who do not have U.S. citizenship have a very real impact. This region harbors one of the major populations of migratory immigrants from Mexico, Central, and South America who work in the agricultural industry. Additionally, part of the national immigration crisis centers on the state's southern border. Calling something "citizen" could be interpreted as unintentionally (or intentionally) discriminatory in our emotionally charged climate according to David and the other individuals who gently but enthusiastically corrected me each time I referred to citizen science.

David's promotion of the use of community science instead of citizen science is understandable and even justifiable as he is not actively involved in the management or development of MCS programs or with the implementation of the MLPA. However, a number of program managers who work with both NOAA and local managing bodies, all of whom are aware of the specifics of the MLPA, use this same logic to support their use of "community science". Hallie, who manages one of the largest and most active citizen science programs in Pacific Grove, emphasized that using inclusive and accessible language was the best way that they know how to 
increase accessibility. Hallie told me "But I think because the community part really means everybody and intends to include everybody... but as of right now, that's the best term to use." David, as a retiree and MCS participant, does not directly work with the MLPA and as a result is not necessarily aware of the legal mandate to implement concrete measures to increase accessibility. The program managers I interviewed however, are leading me to question how seriously they are taking the prompt to design more equitable and accessible programs.

There are some areas of overlap between community science and citizen science; beyond the obvious name similarities. Both potentially give participants ownership over some aspect of their communities and environments. They allow for increases in scientific literacy as well as environmental awareness. And more collaborative forms of citizen science can involve "citizens" from the very beginning of the design of a scientific investigation instead of only inviting them to participate in the data collection process. However, because the marine citizen science programs which operate within the MBNMS are each housed in federal, municipal, academic, or non-profit institutions that have yet to invite members of the community into the initial brainstorming or planning stages it is inappropriate and irresponsible to call these programs community science. Additionally, as I learned during my interviews with Robert and Angela engaging groups like fishermen or funding more accessible forms of MCS like the LiMPETS program are still challenging and critical gaps in the approach to MCS within the MBNMS. 


\section{If MCS is an experience, what did I experience?}

I set out in this thesis attempting to get to the bottom of what exactly MCS is for those who participate in the MBNMS. I chose to triangulate between a number of

research methods in order to

analyze my data, and so I chose to

use participant observation in

order to see what is actually

happening on the ground with the

MCS programs I considered. I

used participant observation to see

whether what I was being told in
Figure 3: Map of the MPA Watch Survey route I did with David Source: Google Maps

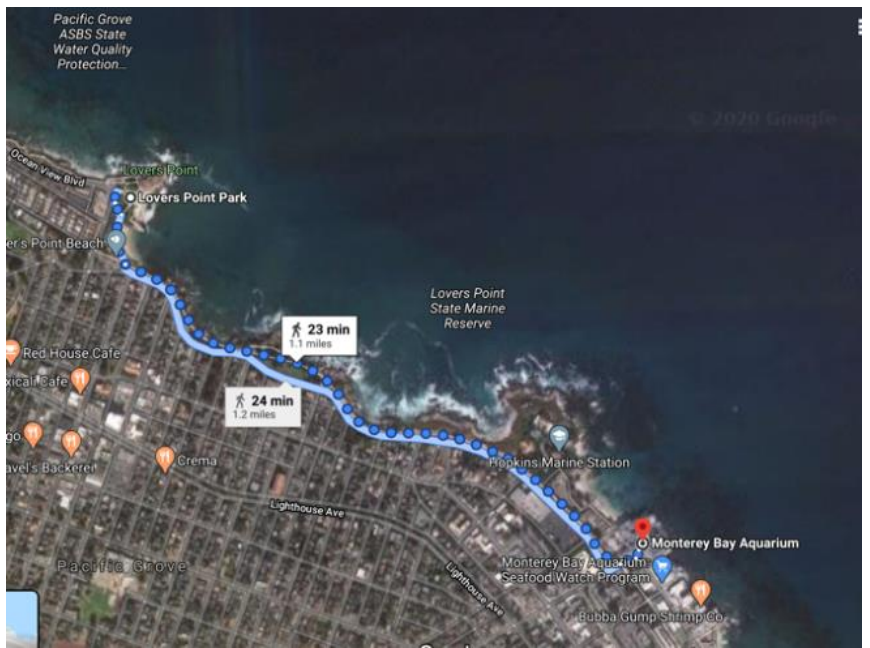

Figure 4: MPA Watch survey sheet

MPA Watch Data Sheet - Pacific Grove Museum of Natural History

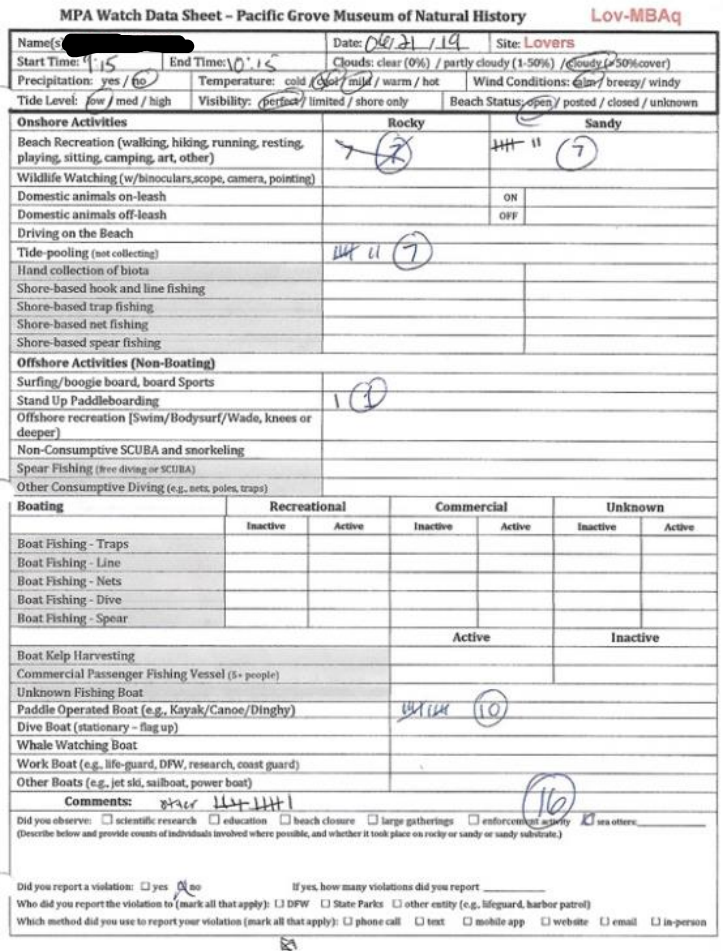

interviews and what I read in the

literature actually matched up with

what is happening on the ground.

The first instance of participant

observation I undertook was early in

my data collection season. In fact, it

was the first weekend I spent in

Monterey, and I had just conducted my

first three interviews. David had

invited me to conduct a MPA Watch

survey with him on a Saturday

morning in early June and I eagerly 
Figure 5: Harbor seal colony on Point Cabrillo Beach, Authors personal photos

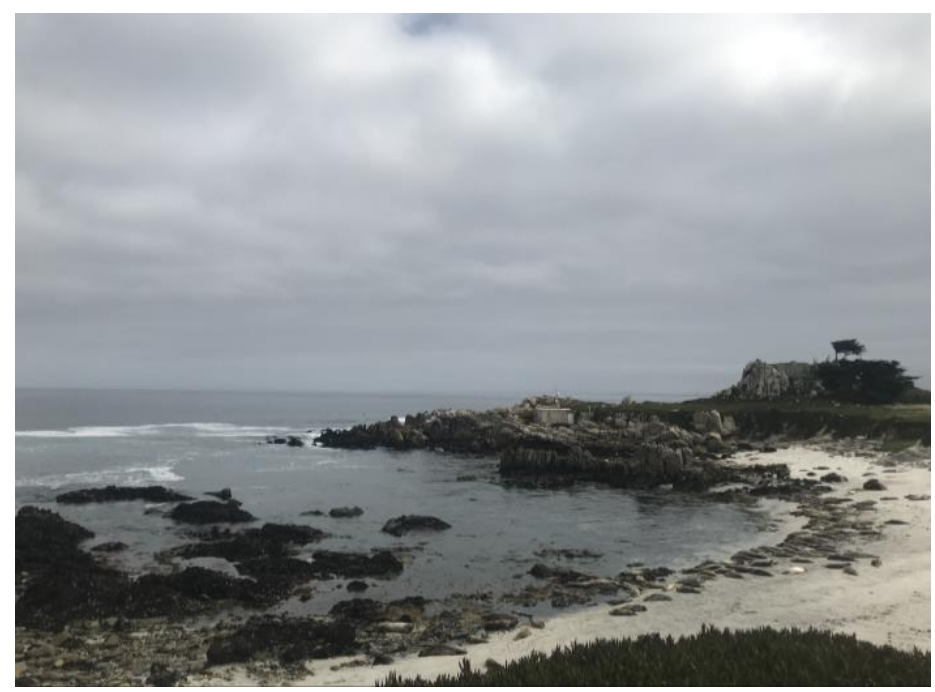

accepted as it was an

unprompted invitation and I

was excited to see the "king

of volunteers" in action. We

chose to meet at the Pacific

Grove Natural History

Museum at 10:00 am on what turned out to be a cool, foggy

morning, typical for Monterey in early June. It was exactly the type of Monterey

morning that has been written about and documented by scholars, authors, and naturalists for centuries. I was incredibly nervous getting out of my car and walking up to David, but I was quickly put at ease by his congenial nature and the enthusiastic hug that he greeted me with. I wrote in my reflective notes following our MPA Watch Survey "Spending time with [David] was like spending time with a loving grandpa who is sharing a beloved hobby or tradition with his family."

David and I conducted an MPA Watch survey at Lover's Point which entailed a 1.2 mile walk from the rocky tip of Lover's point along the Monterey Bay Coastal Trail down the coast to the Monterey Bay Aquarium (Figure 3). With a pair of binoculars and our MPA Watch Survey form David and I set out along the Coastal Trail passing two state MPAs along the way. Conducting a MPA Watch Survey entails documenting the recreational activities you see occurring along the shoreline and offshore including any type of fishing or collecting as well as any MPA regulation 
violations you witness (Figure 4). Additionally, we documented all of the sea otters we saw floating in the kelp rafts just off-shore.

Our survey had barely started when David stopped us in our tracks and excitedly pointed out an otter mom and pup he had spotted just off-shore, something he would repeat 16 more times during our walk. In addition to pointing out otters, he showed me the black oyster catcher rookery which nests just above the pupping harbor seal colony that resides on the Point Cabrillo beach, only 200 meters down a short cliff from the Stanford Hopkins Marine Station (Figure 5; Figure 6).

The survey ended up taking 3 hours total and was one of the most delightful experiences I have ever had. Being an active diver and hiker, I consider myself fairly observant, but compared to David I felt like I had never walked along a shoreline before. The expansive knowledge he had was honestly overwhelming. Between

Figure 6: Hopkins Marine Station Laboratory, Authors personal photos

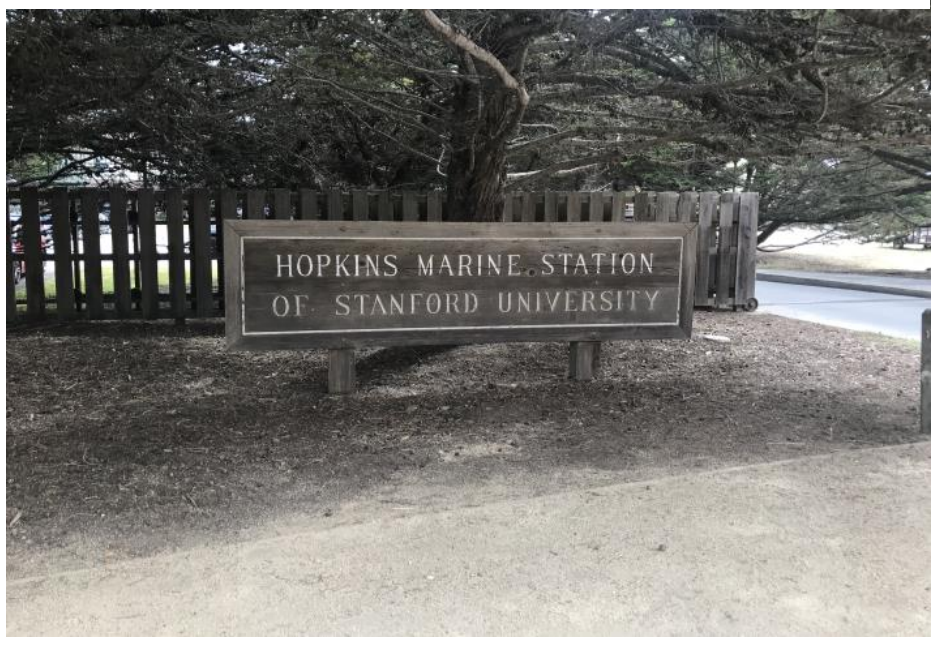

stopping every few feet to

point out another creature or a new animal behavior being exhibited it was an entirely different experience of the Monterey Bay shoreline than I had ever had before; despite having walked the same stretch

of coastal trail a number of times as a child. In terms of accessibility, having also participated in Reef Check and REEF surveys which are highly exclusionary MCS programs, this MPA Watch survey appeared on the surface to be highly accessible. 
Requiring only the ability to cover the 1.2 miles between the two points, a pair of binoculars, and a survey form which can be printed from a Google Drive folder there is little in the way of physical or financial barriers posed by this experience. However, the MPA watch survey forms are unfortunately not available in multiple languages unfortunately.

This participant observation experience with David opened my eyes to how truly passionate and knowledgeable about the ocean, and MPAs, many MCS participants are. David's face was literally alight with excitement during most of the survey and every time he pointed something out to me he appeared to jump up and down with excitement.

\section{What is citizen science in the MBNMS?}

In the introduction of this chapter I referenced the fact that I asked each individual I interviewed to give me their definition of citizen science. The responses I got, while varied, often had numerous similarities. For example, three individuals immediately "corrected me" and asked that we call it community science for the rest of the conversation which then made explaining why they prefer to call it community science a topic we spent a greater amount of time on later in the conversation. It also allowed me to gauge what each individual's relationship to citizen science was and whether or not they had ever critically thought about what citizen science is.

The responses I received to this question allowed me to identify a few critical terms which all of my interview candidates used in their definition of citizen science. These included: "people", "community", "data collection", "non-professional”, 
"scientific process", "monitoring", and "non-academic". "Data collection" or "collecting data" stood out to me when considering each answer to this question as it was mentioned by more than half of my interview subjects in their definitions of citizen science. As a result, my adapted definition of citizen science, which is localized to the geographical space of the MBNMS from these interviews is as follows: citizen science is scientific research in which community members, meaning any interested individual not just those who have the luxury of excess time or income, who are oftentimes non-professional scientists support the data collection and monitoring efforts of ongoing scientific endeavors.

Based upon my interviews as well as my literature review and other research I have chosen to continue on with this qualified use of "citizen science" instead of "community science". I do not discount those who prefer the term community science. Rather, I believe it would be a disservice to the efforts being made to make these marine citizen science programs more inclusive and accessible as it is more of a bandaid solution than actual concrete changes. I do believe that in the future these programs, particularly those run by the California Academy of Science and the Pacific Grove Natural History Museum as well as MPA Watch, do have the potential to become actual community science programs fully owned and developed by coastal communities. However, at the current moment they cannot be defined as such and so I use my adapted version of "citizen science" to define these programs.

It is important to note that over half of the individuals I interviewed immediately responded with some sense of surprise and slight shock to this question of definition. "Oh gosh, great question, and I've never really thought about it" 
demarcated six of my interviewees immediate responses! These responses were often accompanied by a great deal of shifting in seats, fidgeting of hands, as well as the occasional sharp inhalation- lean back- and stare off into the distance. It was not my intention to make my interview subjects uncomfortable right off the bat, but I do believe it highlights an incredibly important reality facing everyone involved with marine citizen science programs in California. This reality is that 10 years on since the final implementation of the MLPA, practitioners, academics, and participants are all still struggling to truly identify what marine citizen science is and what its place in the marine conservation puzzle actually is. 


\section{CHAPTER 3}

\section{Protected areas and Marine Citizen Science: what's going on in California?}

Marine protected areas (MPAs) are one of the most commonly used tools in marine conservation and management. Their implementation also often directly impacts humans and communities as the vast majority of MPAs around the world are directly adjacent to populated coastlines within a nation's exclusive economic zone (EEZ). As a result, MPAs, which often restrict recreational and commercial access, can become sources of conflict and non-compliance by residents and commercial entities whose recreation and commercial activities are restricted. This point in particular has been a source of trouble and conflict with the implementation of MPAs on the California coast between fishermen, conservationists, and managers (OrdoñezGauger, Richmond, and Hackett 2018).

These points of conflict are often exacerbated by a failure to involve communities in the planning, implementation, and management of MPAs. Two bodies of evidence spurned the revamping of California's MPAs. The first is that increasingly, scholars have identified community engagement with the MPA planning, implementation, and management processes as well as regular outreach and community engagement as increasing the likelihood of MPA success (Dalton 2004, Stern 2008, Mahajan and Daw 2016). Secondly, MPAs designed as a system of connected networks increase the likelihood of ecological success (Carr et al., 2017). As a result of increasing evidence that community engagement with the entire MPA planning, implementation, and management process the MLPA led to the redesign of 
Figure 7: Placard denoting the Monterey peninsula's MPAs, Authors personal photos

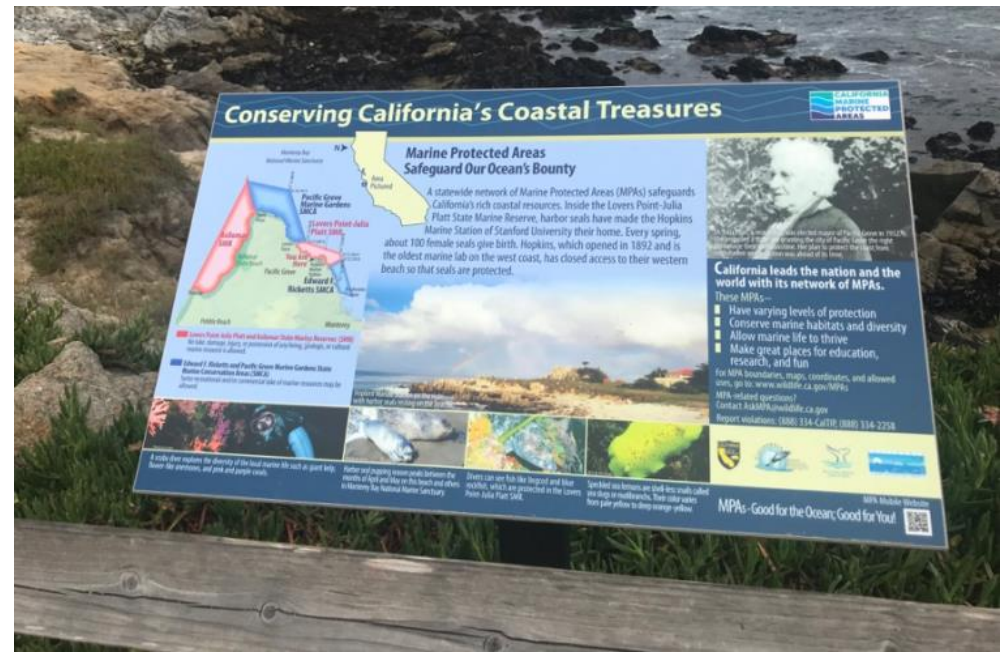

California’s MPA system

into a network of linked

MPAs to designed to

increase ecological

connectivity and success

as well as opportunity

community involvement

(Figure 7).

MPAs are the backbone of this thesis both in terms of their spatial relevance and legal status in California. Without the MLPA directing California's environmental agencies and partners to redesign and reimplement a new MPA network I am doubtful that MCS programs would play as big of a role as they do today. This chapter will be a discussion of this context including exploring what an MPA is, what the MLPA is and the impact its direction has had, how the Monterey Bay National Marine Sanctuary (MBNMS) as a type of protected area fits into this conversation, and why MPAs and MCS are increasingly used as a two-pronged approach to marine conservation and community engagement.

\section{What is an MPA?}

The International Union for the Conservation of Nature (IUCN) defines an MPA as "involving the protective management of natural areas according to predefined management objectives" (IUCN Protected Areas website accessed February 
20201). These pre-defined management objectives can vary from protecting and conserving a specific single species, protecting sites of cultural or archeological importance, or protection of an entire marine space. These differences are designated by the IUCN through a seven point "Protected Area Categories System". These categories are used by governments, academia, and community institutions to establish and manage MPAs. They are also used to determine whether or not protected areas are actually meeting the standards set by institutions like the IUCN which have been scientifically determined to lead to the greatest conservation outcomes.

While protection and conservation of terrestrial spaces through protected areas like National Parks and National Monuments became a priority for the wealthy monied elites in the U.S. in the 19th century the concept of protecting the ocean in the same manner did not become a priority until the mid-20th century. According to Laffoley et al., the earliest MPA, which meets IUCN standards, was the Royal National Park near Sydney, Australia in 1879 (Laffoley et al., 2018). Laffoley then goes on to identify the first MPA in the U.S., Fort Jefferson National Monument in Florida, which was designated in 1935 (Laffoley et al., 2018). Additionally, one of the other earliest MPAs in the U.S. was the Hopkins Marine Life Refuge (Figure 4). Designed and implemented by Julia Platt, the first mayor of Pacific Grove, in 1931 it is an MPA which still exists in California today and in which I participated in an MPA Watch survey as part of my data collection (Palumbi \& Sotka 2011).

1 I have chosen to use the IUCN definition of MPAs as it is believed to be the most scientifically sound definition as well as the most widely accepted by MPA managers, scientists, and conservationists. 
MPAs, when legally gazetted,

ecologically representative,

appropriately designed, and properly

managed have been proven to more

effectively meet conservation targets

including species and habitat

recovery (Laffoley et al., 2018;

Gleason et al., 2010; Fox et al.,

2013). Of particular importance for

this study is the role community

engagement has on the effectiveness

of MPAs. Engagement with the

communities and individuals who

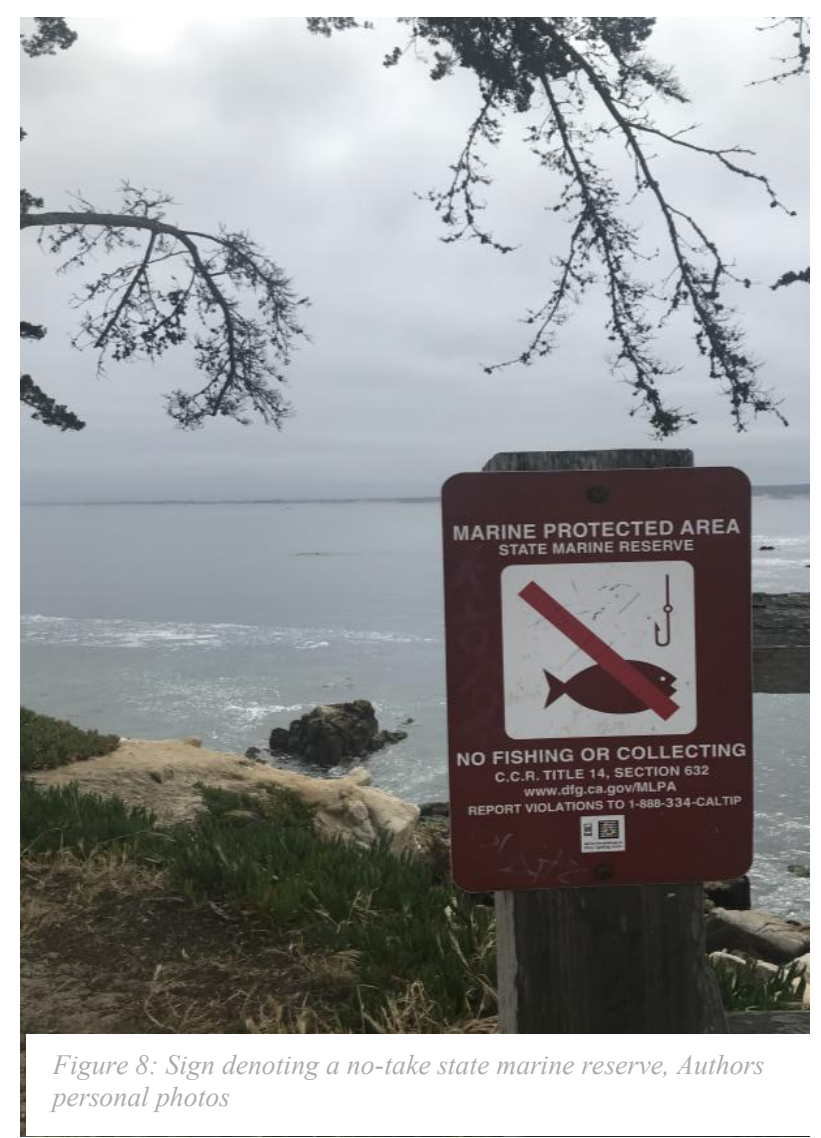

recreate, live, or subsist on the intended protected area must begin even before

implementation (Mascia 2004; Mascia, Claus, and Naidoo 2010; Figure 8). The

perceived legitimacy of a protected area and trust in the managers of said protected

areas are two key factors to increasing voluntary compliance with protected areas, and

both are inextricably linked (Stern 2008). Individuals who voluntarily comply with

protected area regulations are those who have higher levels of perceived trust in the

managers of protected areas. This perceived trust has been found to be best established

through regular interaction and engagement; like through MCS programs (Stern 2008).

Thus, engaging communities and user groups early in the MPA planning process

increases the likelihood of long-term compliance with MPA regulation increasing the 
chance of overall conservation success. In addition to increasing long-term compliance, engaging communities in the monitoring and management of protected areas can have a profound impact on overall knowledge of the spaces and willingness of individuals to hold others accountable for their behavior in the protected area.

\section{New kid on the (MPA) block: the Marine Life Protection Act}

In 1999 the state of California set out to redesign its approach to MPA management. Prior to this, the state managed its 70 MPAs similarly to the management of state terrestrial protected areas; a method which has routinely proven to be ineffective, inefficient, and inappropriate (National Research Council, 2001; Carr

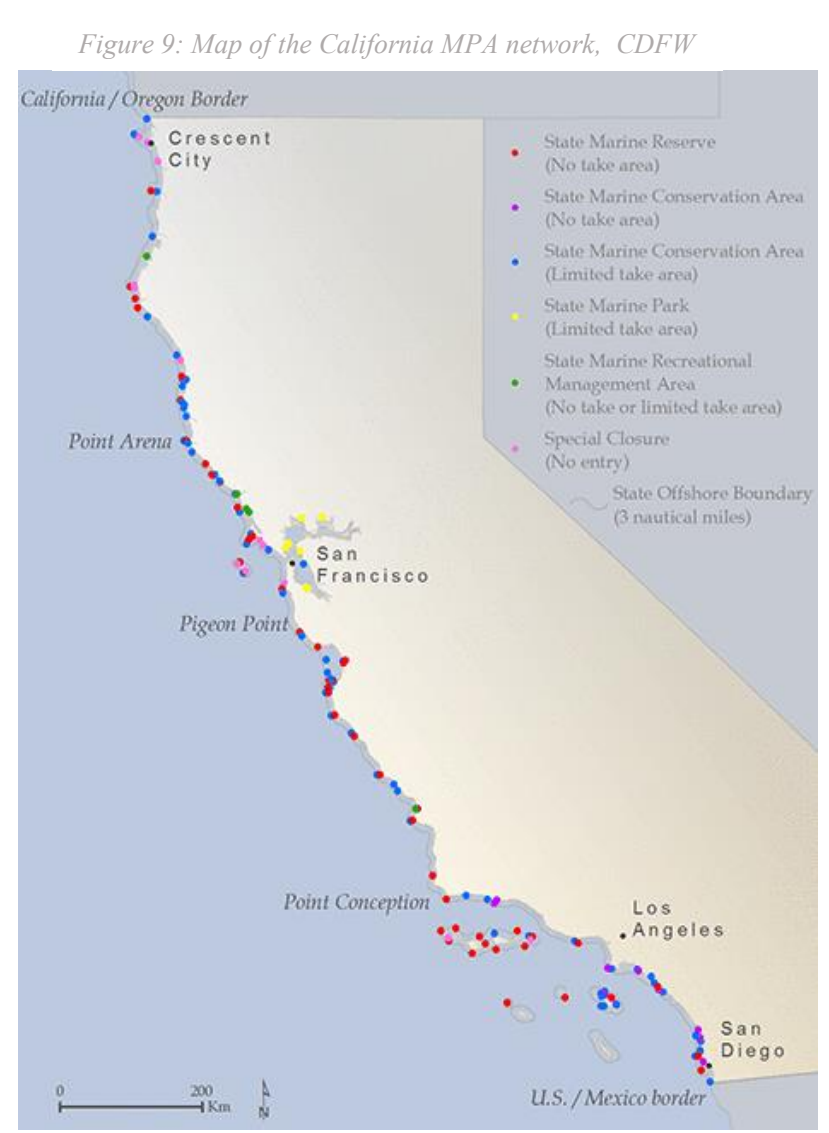

et al., 200; Saarman and Carr 2013).

The initial 1999 version of the

MLPA created mechanisms for the top-down establishment of MPAs in each region. However, this method was met with almost immediate rejection by communities and user groups along the entirety of the California coast (Saarman and Carr 2013). As a result, the legislation was reworked and rereleased in 2004 following intense public

commentary, the formation of the "California Marine Life Protection Act Partnership, 
the election of a new state governor, and a previous attempt in 2002" (Fox et al., 2013).

The MLPA set out to create an equitably and collaboratively designed network of MPAs divided into four distinct coastal regions (five if you include the San Francisco Bay). These four regions are the south coast, central coast, north central coast, and north coast (Appendix 3). In addition to the four geographical regions and direction to form an MPA network throughout the state, the MLPA established six goals to guide the MPA process in each region:

(1) To protect the natural diversity and abundance of marine life, and the structure, function, and integrity of marine ecosystems.

(2) To help sustain, conserve, and protect marine life populations, including those of economic value, and rebuild those that are depleted.

(3) To improve recreational, educational, and study opportunities provided by marine ecosystems that are subject to minimal human disturbance, and to manage these uses in a manner consistent with protecting biodiversity.

(4) To protect marine natural heritage, including protection of representative and unique marine life habitats in California waters for their intrinsic value.

(5) To ensure that California's MPAs have clearly defined objectives, effective management measures, and adequate enforcement, and are based on sound scientific guidelines.

(6) To ensure that the state's MPAs are designed and managed, to the extent possible, as a network. (California Department of Fish and Wildlife 2008, p. 2) 
In an effort to achieve these goals in each of the four regions a series of Memorandum of Understanding's (MOU) were created between the representative regional CDFW offices, scientists, and community representatives who had been chosen to participate in the planning process (Fox et al., 2013). These MOU's required that a region's MPAs must have specific identified ecological goals, objectives, and varied primary purposes2 while achieving the overall goals [of the MLPA]” (Fox et al., 2013 p. 17). There were additional requirements which called for ecological representativeness as well. The requirement that each MPA have a specific and clearly identified ecological goal and purpose as well as be ecologically representative channels the IUCN's guidelines for establishing effective protected areas and departs from historical efforts to protect an area with little regard for a specific conservation target.

The MLPA set out to design a network of MPAs based on the "best readily available science" through the guidance of a team of 48 academic and agency scientists as well as "regional stakeholder groups (RSG)" made up of fishermen, conservationists, recreationalists and other knowledgeable locals (Fox et al., 2012 16). The inclusion of RGUs served a dual purpose both as to increase participative incentive and likelihood to cooperate with MPA regulations (Saarman and Carr 2013; Sayce et al., 2013). This step is a particularly important aspect of the MLPA as numerous studies have identified that stakeholder participation in the MPA design process increases acceptance of established MPAs; particularly in the case of the Channel Island MPAs in southern California (Dalton 2005; Helvey 2004).

\footnotetext{
${ }^{2}$ An MPAs primary purpose is the main conservation target it is designed around. For example, many MPAs along the California coast have a primary purpose of recovering bull or giant kelp species. This primary purpose is something which can be quantified and documented through long term monitoring and comparative studies.
} 
Additionally, as there are only 66 CDFW marine enforcement officers for the entire state of California, developing participative incentive and capacity through stakeholders participating early and through active engagement with MPA stewardship is a critical aspect of the implementation of the newly formed MPAs throughout California.

By 2012, when the north coast region MPAs and structures went into effect, a total of 124 MPAs had been formed creating a massive, nearly 2,000 km long MPA network (Figure 9). A majority of these MPAs fall into IUCN protected area categories Ib, III, V, and VI. The MLPA also resulted in the creation of three types of clearly defined MPAs. These include state marine conservation areas, state marine parks, and state marine recreational management areas. Special closure areas were also clearly defined, though they are not established as permanent MPAs. Rather they are identified and implemented based on ecological need.

At the end of the initial five-year baseline of the central California region CDFW and the California Ocean Protection Council (CA OPC) co-authored the Marine Protected Area Monitoring Action Plan (MPAMAP). This plan was developed based on the data and experiences generated during the initial five-year baseline monitoring period of the MLPA. It clearly identifies the value citizen science provides as a tool for MPA management. It states:

the capacity for citizen science to play a role in MPA monitoring is increasing, as multiple programs improve and standardize their sampling methods to meet traditional scientific standards. Citizen science can take many forms, from casual observations of marine life onshore to organized surveys of 
offshore reefs. Though citizen science is not a substitute for academic research, when suitable, citizen science has the potential to generate large amounts of reliable, cost-effective data while simultaneously creating more informed and invested communities (CDFW and CAOPC 2018).

The Action Plan then goes on to single out Reef Check California (RCCA) the California Collaborative Ground Fish Research Project (CCGFRP), LiMPETS, and MPA Watch as particularly valuable citizen science programs. This recommendation also meets goals one, two, and three of the MLPA, indicating that marine citizen science programs are an invaluable tool for California MPAs.

However, this Action Plan goes into further recommendations regarding the type and structure of marine citizen science programs it sees as providing the best benefit to the CA MPA network overall. Unfortunately, these recommendations take a number of steps backwards in terms of MLPA goal three and the effort to increase the access and equitability of the MPA planning and management process. This recommendation includes two parts which suggest regulating the volunteer sign-up process to "ensure uniform distribution across seasons and weather conditions, with the possibility of paid contractors or employees filling in on days when no volunteers are available" and that "MPA managers and researchers should be integrally involved in guiding and refining the design of citizen science methodologies and protocols in order to maximize their utility in long term MPA monitoring" (CDFW and CAOPC 2018). These two recommendations both suggest taking steps back towards more topdown methods of citizen science which stands in contrast to the goals of the MLPA to increase equitability and access to MPAs. Further centralizing MCS program design 
and removing participants from the development process essentially erases part of the participative incentive the MLPA set out to create. Later on, in following chapters this point will be discussed much more thoroughly. I found throughout my data collection that this unfortunate recommendation already seems to pervade the minds of many program managers who operate MCS programs housed within state and federal institutions.

\section{Why the MLPA and the MBNMS?}

The MLPA is a distinctly Californian piece of legislation. It reflects the states historical predilection towards environmentally forward-thinking legislation as it is the only state in the U.S. to create such a network of MPAs based entirely upon scientific recommendations (Kirlin et al., 2013). However, spanning two of the MLPA designated coastal regions, the central and north central coast, is one of the largest federally managed national marine sanctuaries: the Monterey Bay National Marine Sanctuary. The state of California is actually home to four of the fourteen national marine sanctuaries which exist within the U.S. and its contiguous territories: Cordell Bank National Marine Sanctuary, Greater Farallones National Marine Sanctuary, Monterey Bay National Marine Sanctuary, and Channel Islands National Marine Sanctuary. All together, these sanctuaries encompass 12,145 square kilometers of state

and federal marine space (National Marine Sanctuary Website accessed March 2020). Because of the large overlap between state and federal jurisdictions the MLPA established a collaborative governance framework which is governed by California Department of Fish and Wildlife (CDFW). Due to capacity shortfalls however the 
MLPA allows for cooperation and assistance with "enforcement and educational efforts in select areas where MPAs fall within federal marine managed areas, such as the National Marine Sanctuaries" (Saarman and Carr 2013 p. 44-45). This cooperation and assistance can be seen in the active role played by NOAA in the implementation and management of the central coast MPAs and MCS programs.

The MBNMS was designated in 1992 by President George H.W. Bush; one of six national marine sanctuaries he designated during his presidential tenure (National Marine Sanctuaries Website accessed March 2020). It spans 276 miles of the California coast from Cambria in San Luis Obispo County in the south to Rocky Point in Marin County seven miles north of the Golden Gate Bridge; a distance which covers almost exactly $1 / 4$ th of the California coast (MBNMS Website accessed March 2020). The MBNMS is home to 36 species of marine mammals, 525 known species of fish, 31 phyla of invertebrates, more than 180 species of shorebirds and seabirds, 450 species of algae, 1,276 reported shipwrecks, and 718 prehistoric sites including indigenous heritage sites (MBNMS website accessed March 2020). The MBNMS is a site of incredible richness and has also seen some of the greatest man-made ecological disasters of the 19th and 20th centuries as well as one of the greatest ecological 
recoveries. These include the near total destruction of the southern sea otter population in the 19 th century due to overhunting, the collapse of the west coast sardine fishery in the 20 th century, and presently the destruction of the California kelp forests due to overpopulation of purple sea urchins which result from ocean acidification and warming temperatures (Chiang

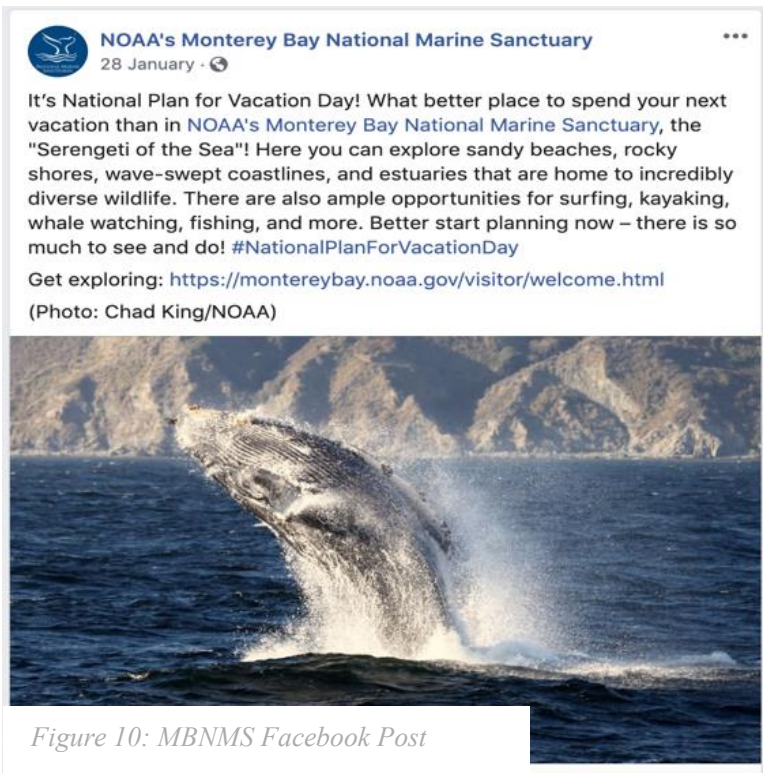
2008; Palumbi and Sotka 2011). However, despite these historical and ongoing crises the MBNMS is regularly described as the "Serengeti of the Sea" due to the plethora of marine life which shelters in the Bay close to shore and is visible to the naked eye (Figure 10).

The MBNMS is also one of few National Marine Sanctuaries which openly prioritizes education, research, and community engagement. The MBNMS is even highlighted on the National Marine Sanctuary website for its citizen science programs. This can be seen through "citizen science" having a representative seat on the Sanctuary Advisory Council as well as the number of sanctuary staff members whose roles revolve entirely around citizen science and community engagement; something not seen in the other National Marine Sanctuaries found throughout California.

Within the bounds of the MBNMS there are 26 state marine reserves and state marine conservation areas (Figure 1). Many of these Sate Marine Reserves (SMR) and 
State Marine Conservation Areas (SMCA) are directly collaboratively monitored by MBNMS sanctuary staff who run National Oceanographic and Atmospheric Administration (NOAA) based citizen science programs including First Flush, Team OCEAN, Bay Net, Urban Watch, Snapshot Day, and Beach Combers. These factors, the geographical overlap, spatial connectivity, and collaborative management, inextricably link the conversation around California's MPAs, the MLPA, and the MBNMS.

\section{We go together like peas and carrots: MCS and MPAs}

MCS programs have been frequently used throughout the Caribbean, Mediterranean, and Australia to help supplement MPA management capacity since the early 1990's (Schläppy et al., 2017). Thiel et al, identified that MCS and volunteer collected data "greatly enhances research capacity, providing an increased workforce over extensive spatial and temporal scales at comparatively moderate costs" as well as increasing capacity when there are "limited human resources" available (Thiel et al., 2014 p. 258). Oftentimes the contributions of MCS to MPAs can read like a one-way street with citizen scientists contributing greatly to MPAs with little mention of what theses citizen scientists get from these experiences. In the case of the MLPA, and as I am arguing in this thesis, the citizen scientists who participate in MCS on the central coast of California gain increased ecological knowledge, understanding of MPAs and California's marine conservation processes, as well as a sense of community and social capital (Dean et al., 2018). 
The contributions of MCS to California's newly developed MPA network are well documented both in academic literature, and as I discovered through my interviews, in public discourse (Freitag, Meyer, and Whiteman 2016; Friewald et al 2017; Friewald et al., 2018). MCS programs including RCCA, LiMPETS, and the Southern California Lobster Research Group 3 all played critical roles in the initial five-year period of the MLPA's baseline monitoring from 2008-2013 on the central coast and 2011-2016 on the south coast (Friewald et al., 2018). The data produced by these programs during these periods were used to generate baseline ecological data which could be used to comparatively analyze the overall success of the newly created MPA networks. These initial periods also cemented the overall value of MCS for the California MPA network as the 2018 review of the MLPA included multiple recommendations for both continued work for MCS programs but also ways CDFW believed MCS programs could be better designed to meet the needs of MPAs as discussed in the previous section. While much has been written about the benefit of MCS participants to MPAs I wanted to garner if these participants gained anything, specifically information about MPAs, from these experiences.

In my interviews with Julia, a graduate student who regularly participates in MCS programs in Monterey and Pacific Grove, and David, I asked each of them what if anything they had learned about MPAs and the MBNMS through their MCS experiences. David shared that he had learned so much he now leads the MPA orientations for many of the MCS programs he participates in. He also carries informational flyers (Figure 11) that he has had printed in a variety of languages to

3 The Southern California Lobster Research Group (SCLRG) is a collaborative research group consisting of fishermen and researchers from San Diego State University, Scripps Institution of Oceanography, CDFW, and recreational and commercial lobster fishermen. 
share with people about MPA regulations when he is out conducting MPA Watch and Baynet surveys. As a retiree, David has shaped much of his social life around his involvement with MCS. Additionally, he has become a veritable fountain of knowledge regarding MPAs, the MBNMS, and ecological phenomenon occurring within the MBNMS and local MPAs. David is, however, an exception and not necessarily a rule as I discovered. Julia, however shared with me that she has not ever

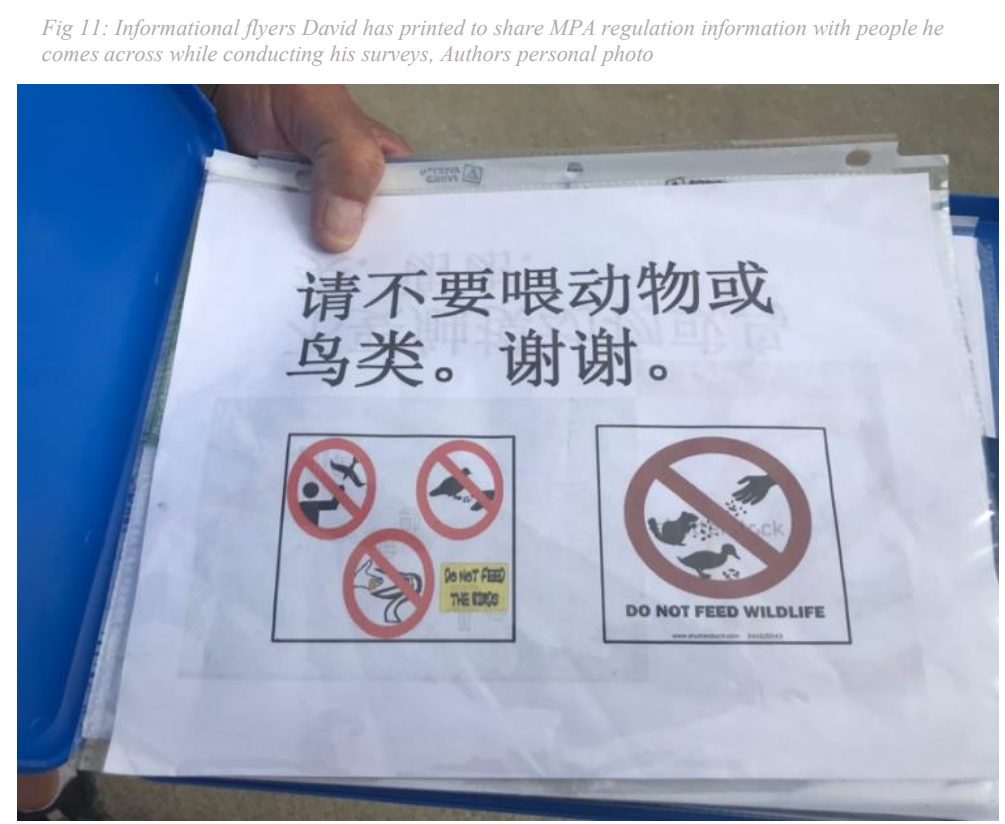
been explicitly introduced to any technical or formal information about MPAs despite regularly participating in MCS programs like First Flush and watershed watch.

These two instances highlight relatively different experiences despite participating in similar, and sometimes the same, MCS programs.

On the program manager side of the question, I found that many of the individuals I interviewed were either trying their best to impart knowledge but often felt pressured by financial or time constraints. These constraints limited their ability to impart information about MPAs or did not recognize sharing information about MPAs as something they felt they needed to be doing. Hallie, a program manager who recently moved to Pacific Grove to run one of the largest MCS programs in the area, 
shared with me that her program takes a different approach than most to sharing information about MPAs and the MBNMS with their participants. She stated that "as most of the programs which operate on the peninsula [Monterey Peninsula] are within MPAs or state reserves we have slides (Appendix 2) in our training materials which explain what national marine sanctuaries are, introduces the MBNMS, then explains what MPAs are within the context of the MBNMS and other national marine sanctuaries"

Based on my interviews it does appear to me that information about MPAs and the MBNMS is being shared with MCS participants, though not necessarily in a reliably concrete manner. As goal three of the MLPA states "To improve recreational, educational, and study opportunities provided by marine ecosystems that are subject to minimal human disturbance, and to manage these uses in a manner consistent with protecting biodiversity" I would argue that currently the MCS-MPA relationship is a relatively one sided one which needs to be reexamined. This is of particular importance if the goal of increasing equitability and accessibility is to be reached as the personal value the MCS programs have for potential participants may not be worth the time and energy individuals would invest in them. 


\section{CHAPTER 4}

\section{Our History, Their Histories, and Realities}

Monterey, Pacific Grove, and Carmel dot the southern end of Monterey Bay and are regularly portrayed as the heart of the central coast of California. They are also often portrayed as small, tight-knit, and environmentally conscious communities for whom environmental consciousness is a constant factor to be consider, particularly in popular media and literature. Take John Steinbeck's Cannery Row, Liane Moriarty's Big Little Lies, and Roger Rosenblatt's Time magazine article from 1998 "Sylvia Earle: Call of the Sea" for example. All of these literary works document both the deep emotional hold this region has on both residents and non-residents alike as well as the colorful and vivid language used by authors and artists alike to describe this region. The past decade and a half of writing, art, and media which have focused on this region have painted a beautiful picture of the region in the public's mind. By extension, this has made the rapid growth of marine citizen science (MCS) programs seem like a reasonable extension of the community's interests. For example, you regularly see Bay Net volunteers4, in their bright blue windbreakers with a pair of large binoculars camped out along the Monterey Bay Coastal Trail monitoring the harbor seal colonies at the Hopkins Marine Station beach as well as beckoning passing joggers and walkers to stop and take a look.

Very few of the curious visitors to the Monterey Bay Aquarium, which sits only a few hundred feet away from where you find Bay Net volunteers, however,

\footnotetext{
${ }^{4}$ Bay Net is a volunteer docent program run by the MBNMS sanctuary staff. Citizen scientists who volunteer with Bay Net monitor shore birds, seal colonies, and otter populations and record instances of potential human disturbances, entanglements, or other threats as well as act as "docents" and introduce passerby's who may be curious to the marine life which resides on Monterey's shores.
} 
know that it occupies the former Hovden Cannery. The Hovden Cannery was a sardine processing plant which played a key role in the near total destruction of Monterey Bay in the 1940's. They also rarely know that the Stanford Hopkins Marine Research Station sits where a violent and racist act of arson was committed in 1907 against the Chinese fishing community which once occupied the space. This act of arson was committed under the guise of protecting the health of the public as well as the environmental health of the Monterey Bay (Chiang 2008).

These instances of erasure and misrepresentation and many more just like them are just as important as the writing of Steinbeck's many books centered on Monterey. They each played a role in contributing to the current social make up, public discourses, and public facing image of what the history of Monterey and the surrounding communities are. As a result of this there is a tendency for only a very small segment of society, the predominately the wealthy, white, and able. to be portrayed as the public face of marine conservation in this region. However, while there is a great deal of erasure there are successes and stories worth telling. I believe highlighting these successes can help the regions MCS programs engage more equitably with the public an ultimately lead to greater marine conservation successes.

This chapter will address how the carefully curated image of the central coast of California fostered by organizations like the Monterey Bay Aquarium (MBA), Stanford University, and private foundations does not tell an entirely accurate story. I will highlight how as a result of the failure to include the histories of the "others", meaning those who are not white and wealthy pervades this space. And how this 
continues to prevent those who do not fit the "white, wealthy, and retired" mold from actively participating in MCS programs or having access to the regions MPAs.

\section{Erasure of history: Erasure of people}

The erasure of the divisive racial history of the central coast set an unfortunate precedent for the environmental movements of the 20 th and 21 st centuries. The racial divisions of the late 19 th and early 20 th century, propped up by laws like the Chinese Exclusion Act of 1882 and Executive order 9066 which called for the internment of Japanese Americans during WWII, still exist today in different form. Information about these events, until recently, had to be purposefully sought out. It was not a priority for institutions like the MBA to share the "other" side of the story. Throughout my interviews I attempted to determine what the general level of understanding of the history of these communities was amongst MCS program managers and participants was and unfortunately, save for a few exceptions, the general level of understanding was extremely low.

In the 1850's Chinese immigrants began settling on the Monterey peninsula and quickly found lucrative business opportunities in hunting abalone and fishing for squid and sardines. At the same, wealthy railroad men began developing large resorts along the coastline as well. These two groups unfortunately collided at the beginning of the 20 th century. In an effort to push the Chinese fishing community out due to rapidly growing racist sentiments local white business owners began publishing vitriolic "letters to the community" claiming the Chinese community and their fishing methods posed public health hazards (Palumbi and Sotka 2011; Chiang 2008). 
Unfortunately, this came to a head in 1907 when the Chinese fishing community was burned to the ground in an act of arson. Ultimately, the displaced community was permanently pushed off of the Monterey Peninsula when the newly burned land was sold to Stanford University to develop a marine biology lab (Palumbi and Sotka 2011; Chiang 2008).

While the Chinese fishing community is long burned down a new community

Figure 12: Lettuce fields in the Monterey Valley Source: Authors personal photos

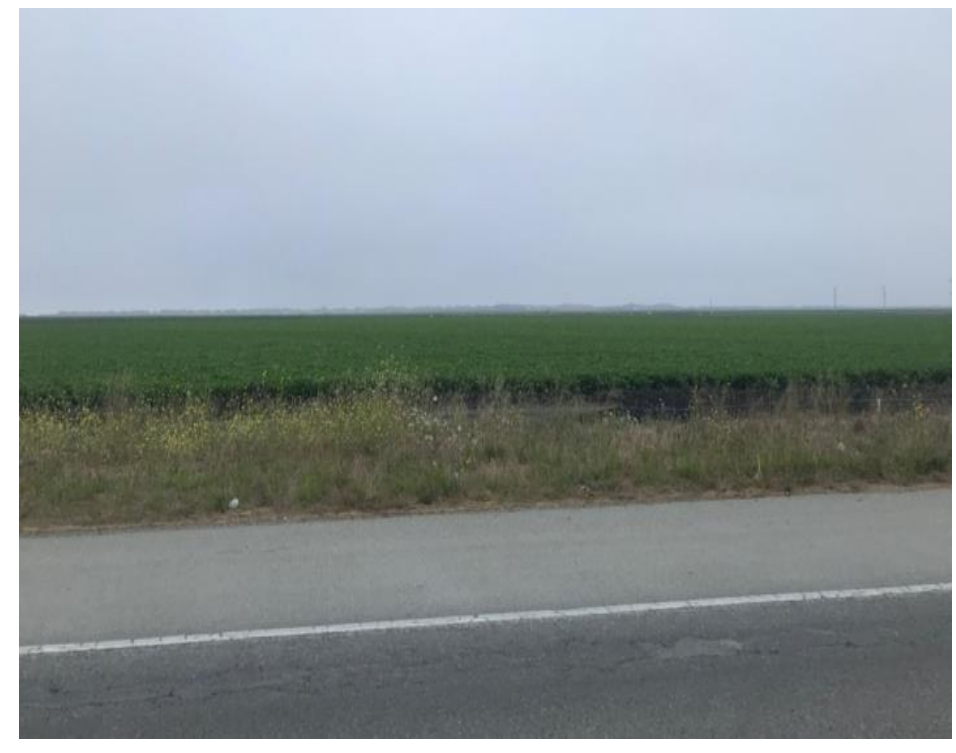

has become the backbone of

the region; Latino

communities who work in

the agricultural power center

that is the Salinas Valley.

About 10 minutes north of

Fishermen's Wharf on

highway 101 is the town of

Seaside. Here is where the

view starts to shift from the Spanish colonial and Victorian architecture which dominates Monterey and Pacific Grove to a large shopping center with a Home Depot, Chipotle, and K-Mart and then to farmland which stretches beyond eyesight.

The Salinas Valley region, encompassed within Monterey County and bordered by Santa Cruz County, produces $\$ 2$ billion worth of agriculture annually and is the fourth largest agricultural county in the state (UC Davis VRIC Website accessed February 2020). This area of 220,000 acres is some of the most productive agricultural land in the country producing approximately $2 / 3$ of the lettuce and 
strawberries consumed in the U.S. (Farm Bureau of Monterey County website accessed February 2020). All of this agriculture takes place within 20 miles of the coast and the MBNMS. Yet when one thinks about Monterey Bay or conducts a Google search they are flooded with images and articles about the MBNMS, Cannery Row, the Monterey Bay Aquarium, Pebble Beach Golf, the TV show Big Little Lies, and fancy weekend getaways. Ironically, most people who visit Monterey do not know that Cannery Row is actually the site of one of the greatest ecological disasters the U.S. faced in the 20th century; the collapse of Monterey Bay's trophic system due the depletion of the sardine fishery and decimation of sea otter populations.

Monterey, its surrounding communities, and the MBNMS have an intentionally curated image that is a century and a half in the making. This coastline encapsulates the deeply entrenched social divisions which began at the time of Monterey's colonization and still exist today. Connie Chiang states in her 2008 book Shaping the Shoreline "the coastline came to reflect contending visions for nature and society - divergent views about the types of people and activities that should occupy Monterey's shores" (Chiang 2008 p. 12). Starting with the development of luxury resorts like the Hotel Del Monte in 1880, a fight for the image of this region began. As the well-to-do tourist industry designed for the early tycoons of what today is referred to as Silicon Valley began to grow, led by the Pacific Improvement Company, working class immigrant communities expanded as well. Many of these communities began, like the Chinese and Japanese fishing communities, began to be subjected to targeted racist attacks in an effort to push these communities out of their residences along the coastline (Chiang 2008). These attacks included claims that their fishing 
methods, the same methods used by white fishermen, were environmentally harmful, that "squalid living conditions" were a public health hazard, and that Chinese women who worked alongside men in their fish processing efforts contradicted the Victorian gender roles of the day and negatively impacted perceptions of the entire region (Chiang 2008).

Continuing into the first half of the 20th century, Japanese fishermen were soon subjected to similarly racist attacks; many of which were prompted or supported by state and federal government initiatives. As WWI and WWII increased demands for food and fishmeal, the rich sardine fishery found in giant schools along the entire central coast region was looked to as a resource to be exploited and eventually decimated. The sardine fishery found within the boundaries of the present day MBNMS was one of the richest fisheries to ever exist within U.S. territorial waters (Palumbi and Sotka 2011). However, the fishery collapsed within 40 years of its initial commercial exploitation, leaving Monterey Bay ecologically decimated much the same as the slaughter of the resident southern sea otter populations 100 years prior. The intensive extraction of the sardine fishery, as well as the destruction of the otter, abalone, and whale populations during the 19th century along with the growth of the elite tourist industry left Monterey Bay (and much of what would become the MBNMS) in ruins. It is not worth rewording in my own terms what this destruction was like, as Palumbi and Sotka paint a vivid image of the destruction and overall decline in prosperity during the time following WWII using language similar to that which was used only fifty years earlier to describe the richness of Monterey Bay and the freshness of the sea air: 
Gone were the Chinese villagers, drying squid, and abalone. Gone were the glass bottom boats at Lovers Point and the summer tourists laughing on the train from San Francisco. The grand hotels no longer echoed with activity but loomed dark or burned to the ground. The shoreline of Monterey, once the launching point for a prosperous fishing fleet, was roofed over by tin and planking, the thick legs of the derelict canneries pounded into the living rocks of the coast. The gulls roosted still on the tin gables of the canning factories, fighting over fish scraps looking in vain for a living sardine to make a meal. The shore still stank of diesel oil. The rocks still stank of fish. (Palumbi and Sotka 2011 p. 109)

However, the extreme destruction of the first half of the 20 th century did not last long. Just like systemic racism and overconsumption, conservation and environmental stewardship have a long history throughout California, and it has a particularly rich history in the central coast region.

Starting with the Chautauqua Nature Study program of the 19th century the "Pacific Coast Assembly of the Chautauqua Literary and Scientific Circles" (CLSC) instituted a "summer school of science" in Pacific Grove in 1880. The CLSC introduced residents to "marine zoology", terrestrial ecology, and scientific processes of nature. The CLSC also provided equal education to both male and female residents;

\footnotetext{
${ }^{5}$ The CLSC is an extension of the "Nature Study Movement" based on the Chautauqua reading circles which began in Chautauqua, New York. These groups developed from the neo-Calvinistic view of nature as having a deep rooted place in the American psyche and throughout the $19^{\text {th }}$ century sprang up across the U.S. The first CLSC was founded by John Muir in Yosemite California in the 1870's. (Stanford Marine Laboratory, Chautauqua: The Nature Study Movement in Pacific Grove, California website accessed March 2020).
} 
though only if they were white and belonged to the appropriate Methodist congregation.

Beyond the CLSC several individuals have played a very public role in environmental stewardship within the MBNMS. Julia Platt, the first mayor of Pacific Grove, fought both legally and physically for the protection of Monterey Bay ultimately becoming responsible for the establishment of the areas first MPA the Hopkins Marine Life Refuge in 1931. Next in line came Ed Ricketts, the author of Between Pacific Tides and arguably the father of marine biology in Monterey. Known as a hobby ecologist, or in today's language citizen scientist, Ricketts collected marine specimens from the rich tide pools that dot the shores of Pacific Grove and Monterey and sold them to scientific labs across the country. Eventually Ricketts became known throughout the community as a troublemaker and thorn in the side of commercial fishermen and cannery owners as he regularly raised the alarm about the rapidly deteriorating environment he saw on a daily basis (Palumbi and Sotka 2011).

While Ricketts and Platt are two key individuals who helped to develop a predilection towards marine conservation in this region, a number of major institutions also played a role. Following the ecological destruction which occurred in the first half of the 20 th century two major institutions began to reshape the public image of Monterey: the Monterey Bay Aquarium and Stanford University. Built out of the ruins of the Hovden Cannery and the Monterey Tourism Plan of 1963, the Monterey Bay Aquarium (MBA) opened in 1984 as a monumental symbol of both the incredible richness of the Pacific Ocean but also of the vast wealth and interest in marine conservation in the region. Since 1984 the MBA has hosted millions of visitors and 
introduced them to the wonders of the ocean. It has also expanded to include the Monterey Bay Research Institution and Seafood Watch; two world renowned research and advocacy organizations. The Figure 13: Placard outside of the Hopkins Marine Station, Authors personal photos

Stanford Hopkins Marine Station

is home to Stanford's Marine

Biology department and hosts

dozens of undergraduates,

graduate students, and researchers

at what has become a preeminent

research institution. It sits a mere

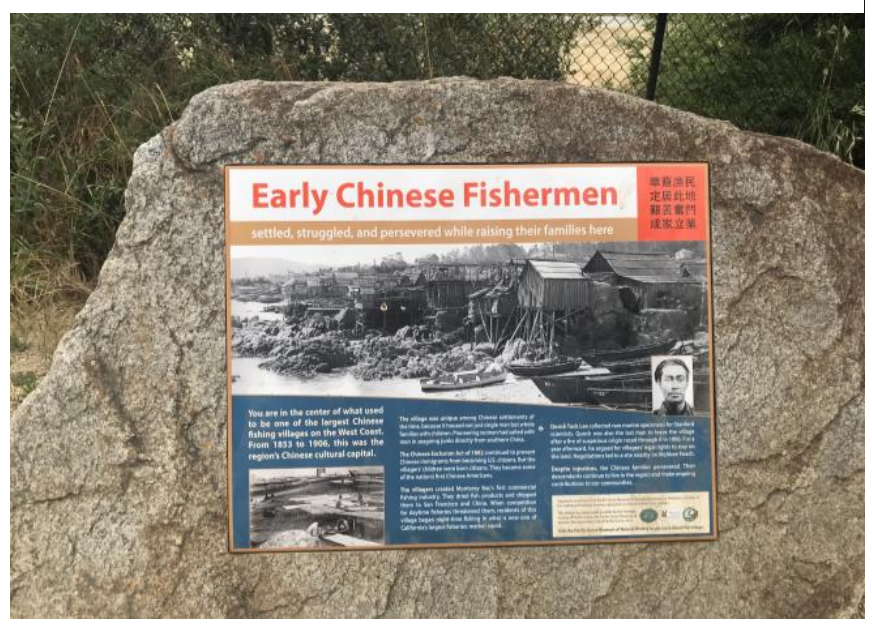

three-minute walk up the Monterey Bay Coastal Path from the MBA on the sight of the original Chinese fishing village.

These institutions, along with the Moss Landing Marine Laboratory, Cal State University Monterey Bay (CSUMB), and the Monterey Tourism Board have played a critical role in reshaping the historical narrative of this space. Until 2008 there was no mention or acknowledgement of the history of the coastal space before it was occupied by the MBA.

Finally, after encouragement by local historical organizations, a placard was put up on one of the original boilers which still exists inside the aquarium to identify the space as the former Hovden Cannery. Additionally, there is a placard (Figure 8) outside of the gate to the Hopkins Marine Station which identifies the site of the original Chinese fishing village as well as the fact that Chinese fishermen have been identified as the first citizen scientists of Monterey because they regularly collected 
specimens for early scientists who had taken up residence to study the Bay. It is worth noting however that this placard was not put up by Stanford or the MBA but rather by the Pacific Grove History Museum; the institution in which LiMPETS, one of the most accessible MCS programs I considered, is housed in.

I asked each of the individuals I interviewed if they knew much about the social and environmental history of the region. In the case of MCS program managers I asked if they shared historical context with those who participated in their MCS programs. The answers all ended up surprisingly similar; some variation of no. The following are three of the responses I recorded to these questions:

Angela: "When asked we will but we don't have any formal trainings for our projects...If we do share history its history related to our institution and work we specifically have done on the coast. But usually its like we don't really have the opportunity to sit people down and talk to them about that [history]." Rachael: "If I'm just seeing someone for three hours at a BioBlitz then it's not important unless it is in a casual way. I think overall however it is important for organizations that are using data and thinking about implementing changes based on cit sci data to understand and know it [the history] as well as the participants."

David: "At the beginning, no, just what I've done."

Based on the responses I shared above it is apparent that while little is actively being shared there is an interest and recognition of the value that sharing the histories of the experiences of the "others" would have. That would at least be a step towards acknowledging the fact that there are historical divisions and factors contributing a 
lack of access to MPAs and MCS programs. Though, while I believe the failure to share these histories is a critical misstep I do not believe it is being done malevolently or on purpose. I believe, as Angela stated in her response quoted above, that capacity is an issue for many MCS managers.

MCS programs in this region are tasked with a lot. They are expected to educate the public about dozens of MPAs, collect scientifically sound and reliable data, oftentimes clean and analyze that same data, as well as recruit, retain, and engage volunteers. Additionally, while MCS programs are directed to help extend the capacity of MPA managers and CDFW staff they are often given little direction from state management bodies beyond that stated in goal three of the MLPA. Resulting in overburdened program managers with good intentions who simply don't have the capacity to be scientists, data analysts, environmental stewards, and natural history educators at the same time.

\section{Imagined Publics}

I believe the curated image of a whitewashed conservation and environmental consciousness which pervades the central coast region has unfortunately led to the formation of an imagined public; particularly within the world of MCS (Yusoff 2018). Imagined publics are audiences for which participatory and experiential programs, like MCS, are designed but that do not actually accurately represent the communities they exist within. Imagined publics pervade the science communication and public engagement realm around the world (Dawson 2015). Over the past decade there has been a growing discussion around imagined publics and science museums particularly 
concerning whether engagement programs are designed to be accessible to lower income and minority individuals or if they are only designed in a manner which contributes to the continuation of the imagined public (Dawson 2015). Limiting factors include language, expense, perpetuated perceptions of minority communities, and reliance on the "barriers model" as a reason for not putting in the effort to include historically excluded groups (Dawson 2014). The barriers model posits that barriers such as cost, geographic distance or attitudinal barriers such as a lack of interest in science, prevent participation by lower-income and minority groups (Dawson 2015).

In the case of the MBNMS the imagined public which has been created as a result of the carefully curated image of the region excludes large swaths of the incredibly diverse communities which reside along the coast; something I would soon learn is actually called the "lettuce curtain". While not a MCS program, the Monterey Bay Aquarium (MBA) is the heart of the public's engagement with both the MBNMS and state run MPAs. Chiang emphasized that while much of the inner workings of the MBA were rebuilt to resemble the former operational cannery it was "the history of the building was rarely anything more than an afterthought" (Chiang 2008 p. 186). However, even after a 2004 renovation during which a placard marking the former boilers of the cannery was placed inside the MBA the focus remains on overfishing and the sardines rather than any human experiences like those of the Latino farmers, Chinese fishermen, or Japanese fish cutters. Additionally, the MBA continues to cater to a predominately white and wealthy audience with a general admission ticket costing $\$ 50.00$; though there is discounted pricing for children of $\$ 40.00$ (Monterey Bay Aquarium website accessed March 2020). As Dawson found in her 2014 study, many 
non-white and non-English speaking individuals find themselves excluded from engagement with experiential science programs due to programming, cost, and lack of engagement (Dawson 2014). The "wealthy, white, and retired" imagined public is catered to in large part because they are the group which is most obviously available and requires the smallest amount of effort to engage with; something which makes sense when thinking from the perspective of a overstretched and underfunded program manager.

As I conducted my interviews this summer something became increasingly obvious to me. MCS on the central coast of California is dominated by white people, or at least it would appear to be. In each of my interviews I asked two questions addressing race and language. The first being "What race or ethnicity do you identify as?" and the second "What is the primary language you speak at home?" These two questions were used to determine the general demographics of those working within the realm of MCS or participating in these programs. Out of sixteen interviews three individuals identified themselves as "Half Asian", "Multiracial, Chinese and white", and "Asian". Only one individual, a MCS participant who identified as "Asian", specified that they spoke Mandarin in addition to English at home on a daily basis.

In Monterey county $55.1 \%$ of the 126,052 recorded households spoke a language other than English at home according to the 2010 Census (U.S. Census Bureau website accessed February 2020). In Santa Cruz County, directly north of Monterey, 32\% of households spoke a language other than English. In San Mateo county at the northern end of the MBNMS, $46.3 \%$ of households speak a language other than English (U.S. Census Bureau website accessed February 2020). Monterey 
County is a predominately Hispanic/Latino identifying county as well with $59.1 \%$ of the 435,594 residents identifying as Hispanic or Latino, the majority of which live outside of Monterey or Pacific Grove (U.S. Census Bureau website accessed February 2020). Monterey also has a small Asian identifying community which accounts for $6.8 \%$ of the population (U.S. Census Bureau website accessed February 2020). Santa Cruz County has a total population of 274,255 individuals of which $34.1 \%$ identify as Hispanic or Latino (U.S. Census Bureau website accessed February 2020). Santa Cruz also has the smallest population of Asian identifying individuals at 5.2\%. San Mateo County, the most populous of the three, has a total population of 718,451 of which $30.1 \%$ identify as Asian and $24.3 \%$ identify as Hispanic or Latino (U.S. Census Bureau website accessed February 2020). Finally, San Francisco which has a total population of 883,305 where $35.9 \%$ identify as Asian and $15.2 \%$ identify as Hispanic or Latino (U.S. Census Bureau website accessed February 2020). In sum, it is apparent that there is a disconnect between the MCS practicing individuals I interviewed and the overall demographics of these places.6 While this is not totally shocking considering the overall demographics of marine science and marine conservation as a whole, it is relatively frustrating when the outcomes of these programs are continuing to struggle and miss the mark to reach these underrepresented communities.

In addition to asking my interviewees about their demographic information I also asked them a series of questions in which I attempted to discern who they saw as the "average MCS participant". While the responses to this question varied there were a number of factors which stood out: volunteer availability, ability to access the beach

6 I also asked each individual where they lived in order to account for any potential differences there and four of the individuals I interviewed resided outside of Monterey, Santa Cruz, and San Mateo counties. They lived in Sonoma, Contra Costa, and Sacramento counties. 
and MCS events, and interest in the ocean. For the more specialized MCS programs like Reef Check, First Flush, or individual REEF surveys, time and schedule flexibility stood out. One of the individuals I interviewed was a marine biologist, Natalie, who has been involved with MCS within the MBNMS since the initial development stage of the MLPA and who runs her own internationally known MCS organization. Identifying time and life stage as a limiting factors Nicole stated, "when they're younger they can better understand [the science], they have time to better understand and fit it [marine conservation] their reality and space especially once they become older and more established". She went on to suggest that while the MLPA was a more collaborative and accessible process, the fact that NOAA still plays a large role in managing such a large space and operating many of the MCS programs which contribute data to California Department of Fish and Wildlife (CDFW) creates a perception of colonialism that can turn off many of the tribal communities, particularly the Amah Mutsun tribal band (Appendix 3 shows all of the Indigenous tribal communities of the central Californian coast).

During my interviews, I asked a number of program managers if the stereotype of MCS participants as being predominately "wealthy, white, and retired" was true. The overwhelming answer was "yes". This failure to engage individuals beyond the easily accessible wealthy, white, and retired folks who seek out MCS opportunities fits into a phenomenon, local to this region, called "the lettuce curtain." I learned of this term during my interview with a member of the MBNMS Sanctuary Advisory Council who served as one of the community representatives. The "lettuce curtain" is a socioeconomic term developed in the late 1990's and early 2000's by a real estate agent. It 
refers to the apparent social and economic barrier which keeps many less affluent communities of the Monterey Bay area, those most commonly involved in agriculture and geographically removed from the coast, more or less segregated and removed from much of the coastal space (Figure 14).

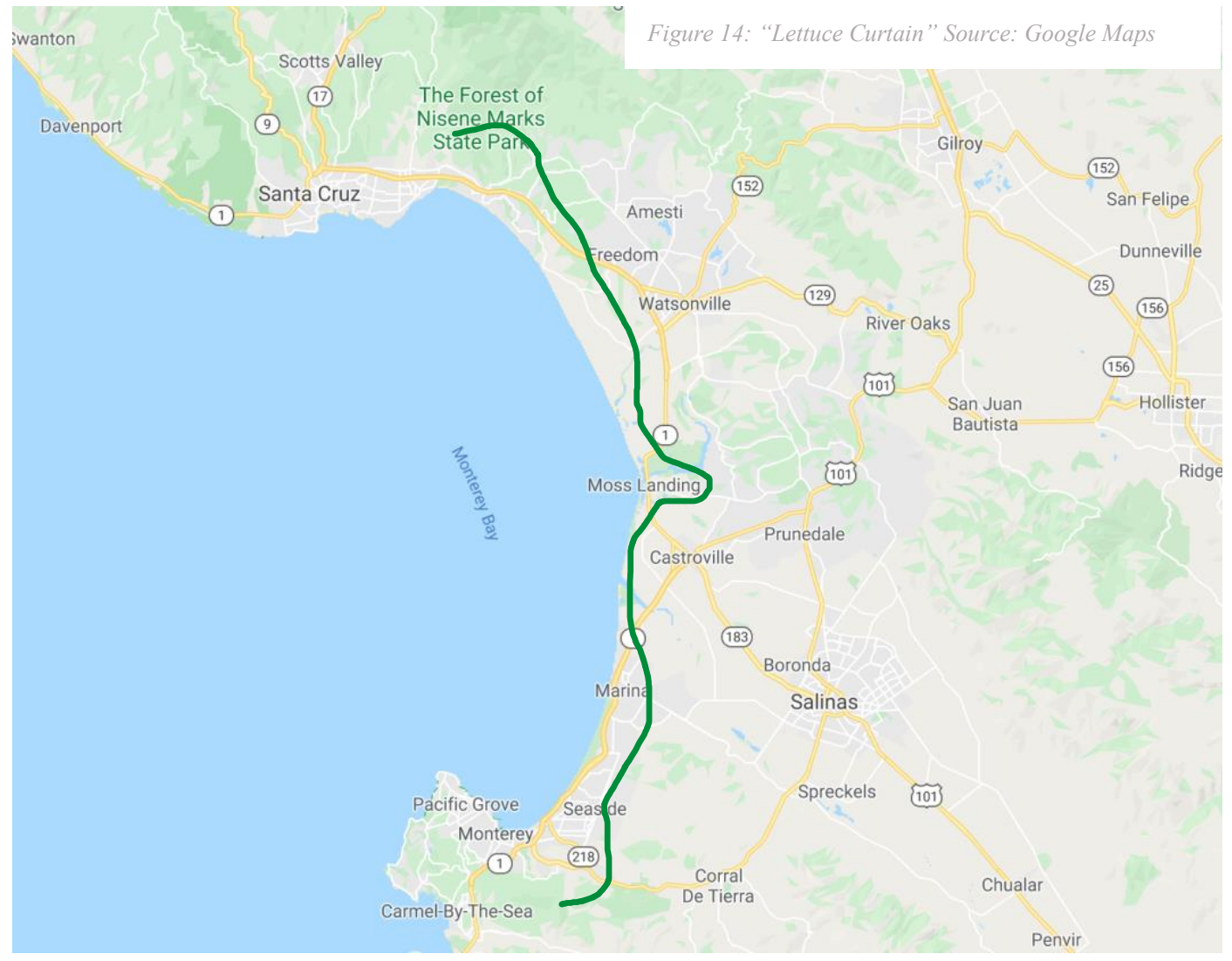

After learning of it, I asked each of the individuals I interviewed if they had heard of this term using the question "have you ever heard of the term the lettuce curtain" and roughly half of them had in some context. Many of them admitted to never having thought of it as relevant to their MCS programs or CS in general. Some stated that they had never heard of it but immediately connected it to MCS and MPAs. Nicole for example stated 'I haven't heard it applied but it makes sense because it's the divide of priorities shaped by people's economics and social status in the area" 
Being personally familiar with both MCS programs as well as the central coast of California I was not surprised to discover that the public which is actively engaging with MCS programs is not necessarily representative of the region's broader demographic make-up. In chapter two I discussed the lack of engagement with recreational fishermen that some of the individuals I interviewed attributed to their perceived "prickly" natures. If one extends that logic then it would appear that MCS managers have in instances of challenge simply chosen not to engage with certain groups though whether this is in order to avoid the work it would take to build these bridges or due to lack of capacity I am still unsure.

\section{What's the opposite of erasure?}

There is a distinct lack of MCS programming, or marine conservation education in general, which touches upon the variety of histories which exist within the MBNMS and the communities within it. While there is growing recognition of this as a problem, as Natalie and Rachel shared with me during their interviews, there are still marked gaps which I believe stem from funding and capacity issues. As a result of this there continues to exist a pervasive idea that the average MCS participant is "wealthy, white, and retired" though increasingly this reality is shifting to include families, young people, as well as increasing racial diversity. While discovering these gaps in access was disheartening at times I was also extremely pleased to learn about the numerous positive instances like Rachael's recognition that the history of environmental engagement and MCS does play a critical role in how MCS programs work with their citizen scientists. The following chapter will delve more deeply into 
the general conclusions I came to as a result of this thesis and will also include more examples of instances of MCS in the region which are in fact crossing many of these barriers and increasing access MCS programs for all who are interested. 


\section{CHAPTER 5}

\section{Actions Speak Louder than Well-Intentioned Marine Conservation \\ Policies}

The role played by marine citizen science (MCS) and the Marine Life Protection Act (MLPA) in the management of marine protected areas (MPAs) in the Monterey Bay National Marine Sanctuary (MBNMS) is a complex and multifaceted one. First, as discussed in the previous section the social and environmental history of the central California coast have deeply impacted the California central coast and have shaped both public and practitioner views and practices of MCS. Second, as well intentioned and ecologically important as the MLPA has been, I believe that it is attempting to do too much in using MCS programs to both increase monitoring capacity as well as increase education and accessibility to MPAs. Third, over the past decade MCS has proven to be one of the most powerful tools MPA managers and conservationists can use. Not only can MCS produce an incredible amount of scientifically sound data it has also increased public knowledge of and involvement in the California MPA network. Therefore, MCS is worthy of time, funds, and effort and should continue to be looked to as a potentially game changing management tool, although there is room for improvement. Finally, while the National Oceanographic and Atmospheric Administration (NOAA) has undoubtedly contributed greatly to overall MPA management capacity and allowed for extensive proliferation of MCS programs, it has also contributed to the continued failure to design equitable and accessible MCS programs. It is my observation that NOAA's status as a federal 
agency also perpetuates a relative sense of acceptance of the current status quo with regards to increasing engagement with MPAs beyond the wealthy and white.

This chapter will serve as a discussion of the conclusions I have developed based upon my research questions, background research, interviews, and participant observation. Each of the four conclusions, referenced above, either directly answers one or part of a research question, or in the case of my conclusion regarding NOAA, reflects a conclusion I came to outside of my research questions.

\section{History and Marine Conservation in Monterey}

One of my main research questions for this study was “Are MCS programs operating in the MBNMS accessible to all potentially interested parts of the community?" As I began digging into the literature, both academic and grey, and interviewing practitioners regarding this question it became clear to me that a major contributing factor to the lack of inclusiveness of MCS is the failure to grapple with the reality of history as discussed in chapter 4 . The history of the geographic space encompassed within the MBNMS, including the areas initial colonization in the $17_{\text {th }}$ century, the arrival of immigrants from China to the region in the 1850's, and the subsequent ecological and social disasters are relatively challenging to uncover. For individuals who are interested this information must be sought out in literature like Palumbi and Sotka's 2011 book, Connie Chiang's 2008 work, or at the Pacific Grove Natural History Museum and is relatively unknown to MCS managers and participants as I discovered during my interviews. 
Attempting to gather information to answer this question took a variety of forms. I asked questions including "Do you share any of the regions history of citizen science or environmental activism with your participants?" and "When do you think the first documented instances of MCS occurred in this region?" Once I learned about the "lettuce curtain" from my interview with Caitlin, a member of the MBNMS Sanctuary Advisory Council, I also began incorporating questions about that into my interviews in ways which felt organic and contextually appropriate if the individual I was interviewing responded to my questions.

The failure to acknowledge the present and historic realities of those people who occupy a space results in present day situations which can disenfranchise marginalized voices and experiences. Natalie, the marine biologist who has built her career around marine citizen science and the central coast MPAs, emphasized that in order to increase the equitability and accessibility of these programs one size does not in fact fit all. She stated that "so long as MCS programs are designed and managed from the top down, which is an increasingly exclusionary practice, they must be intentionally designed for specific audiences."

In the case of the central coast of California, designing programs targeted at students in places like Hartnell Community College reflects the sentiments above and has shown success; as Elizabeth, the NOAA staffer, shared with me. However, in order for these programs to have longevity beyond the two years students attend Hartnell they must be locally relevant to these communities. For places like Salinas and Castroville, which are only twenty minutes inland from the MBNMS, designing programs around the watershed, agriculture, and potential sources of upstream 
pollution appear to be crossing divides between communities though on a short-term scale according to Elizabeth. Though they often end after a year or two due to either a lack of program resources to continue the activities on a regular basis. Elizabeth even identified the water quality programs she operates in Salinas as filling a capacity gap no professional scientists would likely be able to fill due to cost and capacity challenges. Elizabeth told me, "I mean yes, they are the remedy to those issues in a lot of ways because nobody could do that much water sampling with paid people. You would never be able to afford it." Highlighting an unfortunate point of irony in that oftentimes MCS programs create helpful capacity windfalls but they are also still vulnerable to funding issues as well. Embedding MCS programs within existing institutions as permanent programs that are open to the whole community and not just students allows for long term relationships to be developed and increases trust. Additionally, increasing joint funding ventures like the MCS programs which exist immediately on the coast, would immediately increase accessibility for a more diverse array of Californians.

However, programs focusing on students specifically are critically important. Natalie identified students and schools as a key starting point for increasing accessibility and equitability. First, programs embedded in schools create access pathways for students who wouldn't have access to potential careers in science insight into non-traditional forms of science engagement. Secondly, as students become more engaged and interested in science and environmental conservation their families are increasingly exposed to these things as well creating broad based community engagement (Dawson 2014). The need to reach young people, particularly non-white 
young people who do not fit the "traditional marine citizen scientist" mold was mentioned in nearly every single one of my interviews. Programs based in schools or that encourage engagement with younger residents of both coastal and non-coastal communities already exist in Snapshot Cal Coast, LiMPETS, and BioBlitz's; each of which represents a different model of this more accessible form of MCS. As I interviewed MCS program managers who work with each of these three programs it became clear to me that these programs in particular have a higher rate of participation from individuals outside of the stereotype, including families, individuals who were identified as Asian, Hispanic, Latino, and young people often in their 20's-30's.

While these existing programs are not publicly calling for broader recognition of the erased communities and histories of the MBNMS, they are highlighting an important trend; actively and openly engaging with young people from all communities. This is a critical step for increasing the overall accessibility of MCS programs. The existing perception of MCS programs as being dominated and designed for the wealthy, white, and retired is not only impeding the goals of the MLPA but also continues to perpetuate the historically inaccurate and curated image of the coastline of central California. The ocean directly impacts all residents of this region whether they are fishermen, bankers, farmers, or scientists through the weather, tourism, and climate change. So, increasing public access to MPAs through MCS betters the capacity of managing agencies like California Department of Fish and Wildlife (CDFW) by creating personal familiarity and accountability. Additionally, it increases public compliance with MPA policies within more sectors of society and 
creates space beyond the "imagined public" and "lettuce curtain" for everyone thus helping to alter the history of erasure which has existed here for so long.

\section{The MLPA is trying to do too much and it isn't working (or is it?)}

In the introduction, I stated that my research question addressing the MLPA was "What role has the MLPA played in creating an environment conducive to impactful community engagement with MPAs through MCS?" This question was based on my early understanding that the MLPA was designed to "balance the needs of various user groups" and "rectify the perceived shortcomings of California's existing MPA network, including the lack of a coherent unifying plan or clearly designed purposes for each MPA" (Saarman and Carr 2013). The MLPA appears on the surface to have clearly defined and relatively direct goals; after-all it literally has six goals. However, throughout the summer and as my interviews started stacking up I began to notice something when I asked each individual their thoughts on the MLPA. People's reactions to my question was incredibly telling. These ranged from "Oh no, I knew you were gonna ask about this" from Elizabeth to, somewhat confusingly, "The MLPA doesn 't have anything to do with MCS" from Paul, the lead of a scientific lab at a university in the region which works heavily with citizen science data. My immediate conclusion was that everyone perceives of the MLPA as doing something slightly different depending on where they sit in relation to the California MPA network, MCS, or the MBNMS.

The MLPA set out to reinvent the way MPAs are established, managed, and shared in California. However, the social aspect of the MLPA, which allowed for such 
widespread initial success, has unfortunately fallen by the wayside. The end of the initial five-year baseline monitoring period has led to a number of extremely hopeful initiatives to be abandoned or funding to be revoked to meet goal 3 of the MLPA. In the interviews I conducted with Elizabeth and Robert they both expressed their frustration with the funding status of various programs. Additionally, Robert identified the use of MCS as a band aid of sorts in situations where regulatory reform is needed. It is being used by too many parties to do too many things without clearly acknowledging the fact that the MCS programs most relied upon to collect scientific data, like Reef Check California (RCCA), are not necessarily capable of increasing the equitability and accessibility of MPAs and MCS like other programs such as MPA Watch, are able to.

As established in chapter 3, the MLPA is one of the most innovative MPA management plans in the world and the first of its kind in the U.S. As a result, we might expect there to be some kinks. Liza, the executive director of a California marine policy boundary organization, which has been actively involved with the MLPA and California MCS since its inception, summarized this as follows:

California likes to think that there is a lot it can do but there is no one agency in the world that can be relied upon alone to enforce, educate, monitor, and collect data for 124 MPAs particularly when the goals are to actually elevate the health of the ecosystem writ large...So it's infeasible that the fish and game commission and the department of fish and wildlife can do this in a way that a manager from a small island in the Cayman Islands for example could do this. 
The infeasibility of one agency, CDFW, managing 124 MPAs as a network and pursuing all six of the MLPA goals including an aggressive reshaping of the social management approach was not lost on the authors of the MLPA. Hence their purposeful decision to include other agencies (NOAA), non-profit organizations, and academic institutions and use things like MCS to expand capacity.

However, the plethora of organizations involved in the administration of both the scientific and social management processes of the MLPA can easily create a muddied situation in which it is unclear of who is doing and responsible for what. CDFW, which is technically the central managing body of the MLPA, does not take responsibility for the social management aspects. Rather it uses external bodies like the California Academy of Sciences, NOAA, the MPA Collaborative Network, and small MCS and community engagement programs like MPA Watch to help fill this gap. This practice lends itself to further confuse the situation as each organization and group not only understands MCS to be something different, documented in chapter 2, as well as demonstrated by the "community" vs. "citizen" science debate, and what exactly the role of MCS is in MPA management and what types of MCS should be given priority.

So, what exactly is MCS supposed to be doing for the California MPA network according to the MLPA? Per the 2008 MLPA update by CDFW" socioeconomic indicators make it possible to understand and incorporate concerns and interests of stakeholders, to determine the impacts of management measures on stakeholders, and then document the uses and values of the program for the public and to decision makers" (CDFW 2008). This definition then goes on to list the potential roles and uses 
of MCS data which include use data (consumptive and non-consumptive usage), human impacts on MPAs, ecological monitoring and education, and "stakeholder knowledge of natural history and current use patterns and intensity" [(CDFW 2008) emphasis added is mine]. This means that the intent to involve MCS programs in the management of the newly formed MPA network was not solely for the research capacity increase MCS would create but also to openly acknowledge and engage "stakeholders" with the MPAs, the natural history of these spaces, and their current uses. Upon reviewing the intended goals of the MLPA for MCS programs and other public engagement initiatives it is clear that "balancing the needs of various user groups", as stated by Saarman and Carr, was one of the goals. Therefore, it would be logical to infer that prioritizing exclusionary programs like Reef Check California by state agencies and NOAA is a critical misstep in the application of the MLPAs goals. Particularly as all programs, not just those which "look the most like academic research programs", should be funded and given equal footing as Robert shared with me.

As with many programs that are dependent upon government funding those programs which produce the greatest perceived benefits, in this case those who produce the most scientific data, often receive priority when funding choices are made. This situation, which the MLPA has attempted to balance by requiring MCS to be used to increase social access as well, is unfortunately recreated as more traditional and narrowly envisioned perception of what MCS can actually do continues to be favored by funding agencies. In the case of California and the MLPA, funding for MCS programs which are supposed to be carrying out the MLPA goals, comes from 
both the state and the Resources Legacy Fund Foundation, a 509 (a)(3) organization which helps foundations like the David and Lucille Packard and Gordon and Betty Moore Foundations fund marine conservation programs. Unfortunately, these organizations have a strong legacy of supporting highly curated marine conservation programs, like the Monterey Bay Aquarium, just as funds directly from the government often preferentially support programs which produce the perceived greatest benefit of data gathering.

As the scientific and academic community has increasingly come to recognize social acceptance and perceived legitimacy as keys to successful conservation efforts, how exactly this newfound social consciousness should be balanced with scientific goals has proven to be a challenge. The MLPA is an incredibly innovative approach to this question which has undeniably had distinct and remarkable success in incorporating traditionally maligned groups into the management and planning processes (Wiggins 2012).

I heard about many of these successes during my interviews and data collection. However, I also heard about many of these failures and realized that sometimes those involved in the MLPA process don't necessarily understand the role MCS is supposed to play. This confusion is understandable and ultimately forgivable in most cases. As both Liza and Robert said to me, this is all new and has never been done in such a way. Mistakes will be made along the way. But I believe with clarification from managing bodies like CDFW some of these shortcomings can be overcome. This clarification should be based upon thoroughly reviewed and carefully considered feedback from MCS program managers, participants, and observers. It 
should address what the priorities for MCS programs are and what CDFW's explicit needs. And would hopefully be a beneficial step to not only increase the effectiveness of MCS programs but also provide for streamlining which will create opportunities for greater accessibility and equitability.

MCS IS a vital tool for informing MPA policy and increasing equitability: when done right...

MCS is an incredibly powerful tool for more than just scientists and MPA managers. MCS programs have been found to increase scientific literacy, compliance with MPA regulations, social and community accountability, as well as community building (McKinley et al., 2015; Dean et al., 2015). I came out of many of my interviews feeling confused and frustrated with the state of MCS in California. Discovering the failures of partner organizations like NOAA to keep up with the goals of increasing access and equitability, closed access MCS data, and dismissive responses from program managers when asked about engagement with non-white community members (chapter four) could easily have led me to conclude that these MCS programs are not achieving their goals at all. But the reality is more complex, and there is some good news.

Recently MCS programs have played a critical role in identifying key ecological phenomena all throughout the central coast region including sea star wasting syndrome, urchin barrens, and shifts in plankton populations. And even the programs which appear to be the most non-accessible are currently taking concrete steps to engage with marginalized and often erased communities. In this section, I 
provide more examples of what is working in MCS programs and highlight qualities which could be used by those seeking to design successful MCS programs elsewhere in the world.

While MPA managers from the Great Barrier Reef, Bahamas, and Belize have recognized the potential power of MCS for MPA management for many years now, the credibility of MCS in much of the rest of the world is still largely misunderstood or written off (Cigliano et al. 2015). Additionally, perceptions about the quality of data produced by MCS participants regularly impact the willingness of program managers and scientists to use MCS (Friewald et al., 2018). However, particularly in the case of the central coast of California, MCS data has been found over numerous studies to be scientifically sound and just as legitimate as traditionally gathered data (Freitag et al., 2016; Cigliano et al., 2015; Freiwald et al., 2018). Reef Check, LiMPETS, and smallscale collaborative monitoring projects with lobster fishermen in particular have been identified as allowing for diverse and thorough data collection resulting in sound research products with no detectable data quality differences (Freiwald et al., 2018).

During one of my interviews I learned more about both the negative and positive impacts and perceptions of MCS among the research community. Marcia had recently completed her $\mathrm{PhD}$ at a University of California institution studying sea star wasting syndrome along the coasts of California, Oregon, and Washington. Marcia told me that individuals had taken it upon themselves to mail her large envelopes full of hand-written notes and photos documenting instances of sea star wasting they had come across. Marcia went on to emphasize that while there were some challenges for citizen scientists in assessing the severity of cases of wasting that they identified, 
protocols like to those developed by PISCO created a system of standardization which helped to alleviate these challenges, and ultimately allowed for a much larger set of data to be collected than would have otherwise been possible. In addition to the overall capacity increase created by MCS in this instance, Marcia shared with me that marine citizen scientists were the first to identify instances of sea star wasting in the MBNMS in 2013 (Personal Interview August 2019). On the more negative side of things, Marcia faced challenges in initially using much of the MCS data she had collected due to negative perceptions of MCS from members of her committee as well as reviewers when time came to publish.

LiMPETS, the Longterm Monitoring and Experience Program for Students and Teachers, is one of the most active MCS programs within the MBNMS and also one of the most positive. This program is housed in the Pacific Grove Museum and run by a young woman named Hallie. While Hallie and the Pacific Grove Natural History Museum are part of the contingent insisting upon calling MCS "community science", the LiMPETS program is also an extremely positive example of well-designed MCS. There are concrete steps being taken by the LiMPETS program to increase access to their programs like offering "bus scholarship funds to title one 7 schools", actively working with the superintendent of the Gonzales school districts to develop a LiMPETS program for students in that school district to engage in. Additionally, Hallie shared that they are actively developing an ESL version of the LiMPETS

7 Title 1 schools are low income public schools with a specific ratio of students who come from families below federally determined income levels. These schools often receive higher rates of federal or state funding set according to the Elementary and Secondary Education Act and the Every Student Succeeds Act (U.S. Department of Education 2019).

${ }_{8}$ Gonzales is a small, predominately Spanish speaking community in Monterey County 16 miles south of Salinas. 
program. As no study has ever been done to determine what the overall demographics of participation in the LiMPETS program look like, I have no information I can use to assess the impacts of these initiatives. However, compared to many of the programs I looked at during my study period, these efforts show that LiMPETS is in fact taking concrete and seemingly effective steps to increase overall access to their programs for communities which are traditionally left out of MCS programs. While these steps do not create an overall shift in the type of program or allow for participants to be involved in the development of programs specific to their interest, as recommended by Dickinson and Bonney, they do attempt to reach across the "lettuce curtain" in what may be measurable ways (2015).

My interviews with MCS participants crossed the lettuce curtain and exposed me to both the "traditional" MCS participant as well as young, people of color who are just as passionate. One of the biggest things which stood out to me is that these individuals do in fact derive social value and a sense of community from their participation in MCS programs and resulting knowledge of MPAs. But they use this value to give back to these very structures and increase overall knowledge of the ocean within their communities as well. For example, one of my MCS program participant interviewees, David, even went so far as to make copies of the no-fishing and no-take signs posted around the Lovers Point State Marine Reserve and had them translated into a number of languages including Mandarin and Vietnamese. David caries these translated documents with him when he conducts MPA Watch surveys along the coastal trail and shows them to individuals who he sees breaking the MPA regulations (refer to chapter 2 for more discussion of this). 
Small actions like this which allow for individual community members to feel empowered and included in the management and regulation of MPAs through MCS programs help prevent an 'us vs. them' mindset between communities and managing and enforcement agencies. Such actions allow for a sense of ownership and involvement which may not only result in higher levels of compliance and acceptance of protected areas. They may also increase scientific and environmental literacy levels within traditionally marginalized areas and allow for community advocacy and increased environmental justice and access.

\section{The good, the bad, and NOAA: considering the top-down power structures of the MBNMS}

I quickly learned early in my data collection that it would be inappropriate to have a discussion about MPAs and MCS in California without discussing NOAA. Not only does the MBNMS, a NOAA managed and administered space, shape the geographical scope of this study but it also represents nearly $1 / 3$ of the California Coastline and approximately $1 / 4$ of the total MPAs in state waters. NOAA also hosts and collaborates with many of the biggest MCS programs that operate on the central coast including Team Ocean, Baynet, First Flush, Watershed Watch, Plankton Monitoring, and a number of other programs. Additionally, they collaborate with the Pacific Grove Natural History Museum to help administer LiMPETS. They also have become a strong and recognizable access point for residents and community members looking to get involved in MCS programs. 
I did not begin this research fully understanding NOAA's role in MCS in California or NOAA's relationship to the MLPA. Because the MLPA is a state specific policy I believed NOAA acted more as an external body operating alongside CDFW and the MLPA not the intertwined relationship I discovered. Therefore, I did not develop a research question at the start of this study which directly related to NOAA. As a partner agency in implementing the MLPA, NOAA has not only increased enforcement and monitoring capacity, it has also spawned educational initiatives and numerous MCS programs. NOAA's efforts to engage the Latino and Hispanic communities were among the first in the MPA management community. Additionally, the individual MCS program managers who are MBNMS staff are wonderful individuals who are truly working their hardest to develop more equitable and accessible MCS programs.9

However, as NOAA is a federal agency and the MBNMS was implemented through executive order and did not involve local fishermen, community members, or indigenous groups the MBNMS. As a result, it continues to perpetuate long standing perceptions of power imbalance first established centuries ago. These power imbalances can be seen through the sanctuary advisory council (SAC) as well as the apparent discontinuation of programs like the Multicultural Education for Resource Issues Threatening Oceans (MERITO) while claiming they are still active and functional. As a result, NOAA's presence adds another layer of confusion to an already convoluted place.

9 As the MBNMS is a federally established national marine sanctuary, NOAA is the sanctuaries managing agency like CDFW is for California's MPAs. 
As NOAA is a federal agency its programs and staff are managed by and beholden to a different set of standards than those employed by the state or non-profit organizations. For example, I discovered through a number of my interviews that NOAA also is often perceived in a different, more top-down, manner than much of the CDFW implemented measures. Finally, as I discovered during my interviews through the insistence of Elizabeth and Lily (another NOAA staffer) that I call citizen science community science, NOAA staff does not necessarily share the same understanding of what exactly MCS is or what its intended role in California's approach to MPA management should be. As a result, the MCS programs it runs do not always match the goals of state developed programs and the MLPA.

While the MLPA was designed to be a combined bottom-up and top-down process that sought out collaborative groups which were as representative of regional diversity as possible, NOAA and the MBNMS was not instituted in a way that could support this goal. The U.S. sanctuary system implemented structures like Sanctuary Advisory Councils (SACS) as collaborative groups which help recommend methods to increase collaboration and equitability in NOAA managed sanctions but don't actually have veto power over the sanctuary. The MBNMS SAC notably, unlike the other national marine sanctuaries found along the California coast, does not include seats for local indigenous tribal communities. Whereas the Channel Islands National Marine Sanctuary just to the south for example has two representatives from the Chumash Tribe who are active members of the SAC. Additionally, the Chumash Wishtoyo foundation is also actively and openly engaged in the MPA process on the south coast 
whereas there is no apparent active engagement by the MBNMS with the Amah Mutsun Tribal Band.

Having been involved in the MPA process on the central coast since the very beginning of the MLPA and the early days of the MBNMS, Natalie has worked directly with both local fishermen who were and were not consulted in the establishment of different MPAs but also with the Amah Mutsun. I will show more of Natalie's description of the tribal engagement process here, because it unfortunately paints a clear picture of a major failure on the part of NOAA. She told me:

The process disenfranchised a lot of people and interested a lot of others. The whole way the sanctuary was done and set up was very colonial, very white, wealthy person centered. There's all that all up in the sanctuary. So the tribal communities and other user groups in the communities are often really turned off by that because they felt that if they tried to get involved on those [MCS] initiatives that nobody is going to care really anyways and the government will use their involvement as a way to say 'Oh yea, we worked with the tribes you know, we checked our little box here we invited them to three meetings, it was awesome' And then they go ahead and they do something that was completely against what was recommended anyways.

Natalie went on to emphasize how this history of "checked box engagement", particularly on the central coast, has negatively impacted relations between Sanctuary staff, tribal communities, and even fishermen. Ultimately this has manifested in distrust and often disinterest on the part of all involved. 
Based on the short time I spent meeting and interacting with individual representatives of numerous MPAs from up and down the California coast as well as from my formal interviews, I can say that there is a strong push and desire to actively engage with tribal communities and other underserved and underrepresented communities as well. I learned during an interview I conducted with a member of Reef Check's staff, that even Reef Check, the most exclusive and inaccessible MCS program, has begun to collaborate with tribal communities in Washington State to develop survey protocol based entirely upon indigenous knowledge to be used by indigenous scientists Additionally, indigenous led BioBlitzes, Snapshot Days, and INaturalist events are increasingly supported by large organizations like the California Academy of Sciences just to the north of the MBNMS on the Sonoma coast.

The willingness of other national marine sanctuaries and even MCS programs as rigid as Reef Check to actively engage with and seek out ways to serve tribal communities who have historically resided in areas where there are now MPAs makes one wonder; why is the Central California MBNMS so resistant to engaging with tribal communities? This particular question is beyond the scope of this study but when the erasure of tribal and indigenous communities is considered alongside the "imagined publics" discussed in chapter 4 it caused me to consider the potential links between historical colonialism, federally imposed agencies, and the monetary funding structures which support marine conservation initiatives.

Colonialism and capitalism go hand in hand in American history, and the present state of marine conservation which exists on the central coast of California is dominated by capitalist monoliths like the Packard and Moore foundations, which 
fund and manage the Monterey Bay Aquarium, and the RLF which attempt to use "conservation capitalism" to obfuscate the very environmental destruction initially wrought by colonialism and capitalism. As a result, it is not surprising that Indigenous communities continue to be locked out of efforts to increase equitability and accessibility of MCS programs. While these private foundations do not directly fund NOAA or the MBNMS they have helped to foster a social environment in which it is deemed acceptable to continue to fail to actively engage indigenous communities despite more active engagement in other parts of the state by MCS organizations. The MLPA has created a pathway for the implementation of equitably designed and managed conservation policy, and while there are obvious missteps occurring it is critical to highlight successful instances as well. According to my interviews, a major player in increasing collaboration, equitability, and accessibility of California MPAs is the MPA Collaborative Network. This organization acts as a coordinator for the entire state's MPA network and works to regularly bring publicly appointed regional representatives together to collaboratively assess and improve the management of MPAs. These representatives come from 14 designated regions and meet multiple times a year along with CDFW, the California Ocean Protection Council, interested citizens, and funding organizations. The MPA Collaborative Network has a stated mission to "empower coastal communities to advance MPA management and encourage ocean stewardship", a vision of "encouraging civic engagement in local resource management to ensure the health and sustainability of our natural and social environments," and a purpose "to create a cooperative process that encourages participating in decision making and communication, grounded in the 
values of respect for differences and the interconnection between humans and nature" (MPA Collaborative Network website accessed February 2020).

At the MPA Network Collaborative workshop I attended in August 2019, representatives from two tribal communities were present. 10 These individuals both serve as their respective region's co-representatives to the MPA Collaborative Network and shared incredible stories of how in both Northern and Southern California traditional management practices have been integrated into their local MPAs alongside Western management practices. Seeing the representation of the Northern Chumash and Tolowa Dee-ni' Nation in the Network raised an immediate question in my mind; why are there no chairs from the Amah Mutsun tribal band for San Luis Obispo or Monterey? As far as I have been able to discern, there has been little effort beyond Natalie's individual actions to engage with the Amah Mutsun tribal band despite their active role as terrestrial land stewards along the central and southern coasts of the MBNMS.

Another of my interviews with a NOAA sanctuary staff member, Elizabeth, resulted in an anecdote about Hartnell College. Hartnell College is a small community college in Salinas, CA with a predominately Hispanic and Latino student body, which focuses on agricultural sciences. Elizabeth has been running a number of CS programs focused on watershed education and awareness as well as recruiting for Snapshot Day, a statewide MCS initiative which ran trainings around the area:

There's one group of guys, oh my God, they missed the training that I did in Monterey. So they drove from Salinas all the way to San Simeon,

\footnotetext{
${ }^{10} \mathrm{I}$ am choosing to withhold any further identifying information which could potentially be used to identify these two individuals as MPA Collaborative representative information is public information and it would be a violation of my IRB procedure.
} 
which is like a two and a half hour drive to join the training that was down there. It was so funny, they walk into this tiny little center and I was like, you know the center's closed and they're like, no, we're here for training. There was like six guys, six or eight guys that just drove down. So you sort of feel like when you, when, and this is part of that making the connection where you feel like you, like I made a huge deal out of the fact that they did that. Like that's amazing to me just in general.

As Elizabeth was telling me this story, her eyes lit up and she seemed to actually begin bouncing up and down in her chair. Seeing the care and enthusiasm individuals like Elizabeth have when they realize they are making strides to attempt to increase the access minority communities have to MCS and understanding that the desire to participate does exist despite continued belief in the barrier model was a truly heartening experience. I walked out of this interview with Elizabeth feeling hopeful that the MLPA is actually doing more good than harm and is reaching individuals previously forgotten by marine conservation policy.

Unfortunately, my excitement after Elizabeth's interview did not last very long after I learned about MERITO. MERITO is described as "a marine conservation outreach effort comprising local and regional groups that participate in ocean and watershed education programs that serve students, teachers, adults and families living near the MBNMS" (NOAA MBNMS website March 2020). Essentially, MERITO is a guide to increasing collaboration with Hispanic and Latino communities throughout the MBNMS region. However, the original MERITO plan has not been updated since 
2001, does not reflect MLPA goal three, or reference any of the organizations which have grown in the last two decades whose sole purposes are to increase capacity around collaborative engagement. Additionally, as far as I have been able to determine, none of the paid internships proposed in the MERITO plan intended to increase engagement ever actually came to fruition. I attempted to contact the individual listed on the MBNMS as the MERITO Academy Coordinator on four different occasions while collecting data this summer, one of which was an introduction from a colleague, but I never heard back from them. My attempts to garner information about MERITO and whether or not it was operational were all met with hems and haws from others, and statements like "well you're going to have to talk to such and such" person. As NOAA is managed and run federally the prioritization of engaging with the large Spanish speaking minority population in California is not necessarily a priority for a federal agency.

Despite my frustration with MERITO and the apparent misalignment of NOAA's MPA and MCS management priorities I do not wish to write off NOAA as a lost cause. Because NOAA is a federal agency however I believe that the main goals and priorities for NOAA staff and programs run by them do not entirely match the goals and approaches taken by state agencies and non-profit organizations. In the previous section I highlighted the need for reflection and reevaluation to be done by CDFW and all of those involved in implementing MCS programs on the central coast. I believe that NOAA in particular would benefit greatly from such self-reflection done by CDFW as it could allow for clarity between all involved in MCS and essentially "get everyone on the same page". 


\section{CHAPTER 6}

\section{What's it all been about? Final thoughts on MCS, MPAs, and the MBNMS}

Marine citizen science (MCS) in California is only going to continue to grow; particularly as federal and state funding for environmental management capacity is cut. During the three months I spent in San Francisco collecting data numerous MCS programs popped up, seemingly out of thin air, up and down the coast. These programs were often beyond the geographical scope of this project but are still relevant in that most of them identify supporting California's MPAs as a major goal. Clearly, MCS has taken up residence in California and is going nowhere. As I discovered in my interview with Mary, the recent PhD graduate who used MCS data in her dissertation on sea star wasting syndrome, MCS data is still looked down upon in many academic and management circles. However, programs like Reef Check, LiMPETS, First Flush, and Team Ocean have provided data which has been found to be scientifically sound time and time again over the past decade. The increasing acceptance of MCS data as sound and accurate lends itself towards encouraging broader acceptance of MCS as a MPA management tool; just as it has done in places like the Great Barrier Reef where MCS has been used for decades.

This thesis was an interesting journey. What started as an interest in MCS due to personal interest and my experiences as a dive instructor led me to delve deep into the history and current reality of my home state. I grew up on the central and south coasts of California and I often attribute my love of the ocean and present-day curiosity to the summer weeks when I went to visit my grandma who lived in Watsonville, smack in the middle of the Monterey Bay National Marine Sanctuary 
(MBNMS). At the beginning of this process I had an image of Monterey and the coastal towns which dot the MBNMS that was strongly based on my experiences as a child. However, through this thesis these images and memories have shifted as I began to critically examine how exactly these communities engage with marine protected areas through MCS programs. In my effort to answer my overarching question of "how is MCS defined by those involved in the MBNMS and how is it being used to increase the accessibility and equitability of California's MPA network?" I ultimately came to the four following conclusions:

- The social and the environmental histories of the central coast of California have had and continue to have a direct impact on the equitability and accessibility of both MCS and MPAs, and the failure of MCS programs to address these legacies continues to reinforce structural inequities like those which result in the average MCS participant being described as "old, white, and retired".

- The Marine Life Protection Act (MLPA) lacks a clear definition of what MCS is and what exactly the priority for MCS programs are. Additionally, it frequently contradicts goal three and the stated intentions of increasing access by prioritizing MCS programs like Reef Check California and failing to prioritize less traditional programs such as LiMPETS and those which are accessible to communities away from the immediate coast.

- MCS programs are playing a vital role on the central coast of California. Not only have they contributed to successful ecological research and monitoring but they have also allowed private citizens like David to become active ambassadors for MPAs. Additionally, programs like LiMPETS and INaturalist are increasing access points both to MPAs and the coast but also to science and marine conservation as a whole thereby increasing the likelihood of broad social acceptance of MPAs and hopefully the success of California's MPA network.

- The National Oceanographic and Atmospheric Administration (NOAA) is a federal agency, which works collaboratively with state organization to implement the MLPA and as a result adds a layer of "outside" complication to it. As NOAA and the MBNMS are both top down federal structures they are often perceived as contributing to the continuation of inequitable power structures and doing little more than "checking boxes" when it comes to working towards accessibility and equitability. 
Each of these conclusions speaks to a part of my overarching research question as well as the numerous subsidiary questions I developed and spoke to throughout this thesis. While I was able to formulate a derived definition of MCS based upon the cumulative results of my interviews this is not without a caveat as there is no definition of MCS within the MLPA. This lack of clarity and direction contributes to an overall inability of the programs to enact broad and concrete changes leading to increased equitability and accessibility of both California's MPAs and MCS programs.

The greatest takeaway from this research is the third conclusion highlighted above. Certain MCS programs are in fact making a difference. Both in terms of their accessibility and equitability but also on the impact they are having on encouraging engagement with and understanding of California's MPAs. Throughout this thesis I identified qualities of these successful MCS programs and believe they can potentially be replicated elsewhere (Table 3). As MPA managers, marine conservationists, and marine scientists across the U.S. and the world seek to develop their own MCS programs they should take care to design their programs around these particular qualities. 


\begin{tabular}{|l|l|}
\hline Quality & Program \\
\hline Open Access Data & $\begin{array}{l}\text { LiMPETS, REEF, Snapshot Cal Coast, MPA } \\
\text { Watch, Project Aware, INaturalist, First } \\
\text { Flush, Watershed Watch, Team OCEAN, } \\
\text { Baynet }\end{array}$ \\
\hline Financial support for participants & LiMPETS \\
\hline Multilingual materials and training & Snapshot Cal Coast, INaturalist, LiMPETS \\
\hline Centered around schools & LiMPETS \\
\hline Ease of access & MPA Watch, INaturalist \\
\hline Online/Mobile Platform & $\begin{array}{l}\text { MPA Watch, INaturalist, Project Aware, } \\
\text { Snapshot Cal Coast }\end{array}$ \\
\hline Volunteer led- can be done anytime & MPA Watch, INaturalist, Project Aware \\
\hline Place-based program design & Watershed Watch \\
\hline
\end{tabular}

Table 3: Qualities of successful MCS programs

\section{Where I went wrong and you should go next.}

My project happened to be the first of its kind examining the role MCS plays in California MPAs and whether or not these programs are increasing the equitability and accessibility of both MPAs and MCS programs in relation to the MLPA and the MBNMS. And while I am happy with the amount of data I was able to collect and the conclusions I have drawn there are a number of critical points which I was unable to examine whether due to time constraints, lack of capacity, or simply lack of foresight on my part. One challenge I am now distinctly aware of is my failure to include the African American residents of this region in my consideration. I contribute this partly due to my consideration of the region's demographic make-up and recognizing that comparatively African American residents make up a much smaller minority of the population than any other minority group in the region. However, as one of my conclusions and main themes of this thesis deals with the erasure of histories and experiences I am keenly aware of how this is a disservice to not only the individuals I failed to consider in this study but also continues to contribute to their erasure from the 
MCS and marine conservation sphere in California. A second challenge I faced was dealing with the sheer scope and number of MCS programs which exist in this space. As I wanted to discern what was happening holistically I chose not to delve intensely into any one MCS program in order to prevent an overload of information. While I ultimately believe this choice was appropriate given my limited resources and capacity I believe individual programs are worth conducting a thorough analysis of given how prolific they have become.

These two missteps on my part directly inform my recommendations for further research. Research considering the specific demographics of MCS program participants could shed light on whether or not the "lettuce curtain" has been drawn back by the regions MCS programs A second recommendation would be in considering perceptions of MCS and MPAs within various recreational groups (i.e. scuba divers, fishermen, and surfers). A final recommendation for future research would involve analyzing MCS and MPAs from a higher level through interviews with the original authors of the MLPA and original MCS advocates in order to understand the perspectives of those who began this process twenty years ago.

Future research into these topics will hopefully help to fill in the numerous gaps, including those I identified above, left by my thesis. I hope my thesis however will serve as a helpful and appreciated starting point for those looking to understand the complex and interconnected nature of MPAs and MCS programs on the central coast and that some of my conclusions could be adapted to assist in the development of MCS programs in other parts of the country. This thesis was born out of my personal connection to both marine citizen science programs and my childhood spent 
on the California coast. I believe it mirrors the complex nature of marine conservation in this space and I hope it helps to pave the way for future marine citizen scientists and MPA advocates of all types. Afterall, the best way to create advocates is to help them experience that which needs advocating for and come to know it personally. 


\section{APPENDICES}

Appendix 1: Map of MLPA established coastal regions

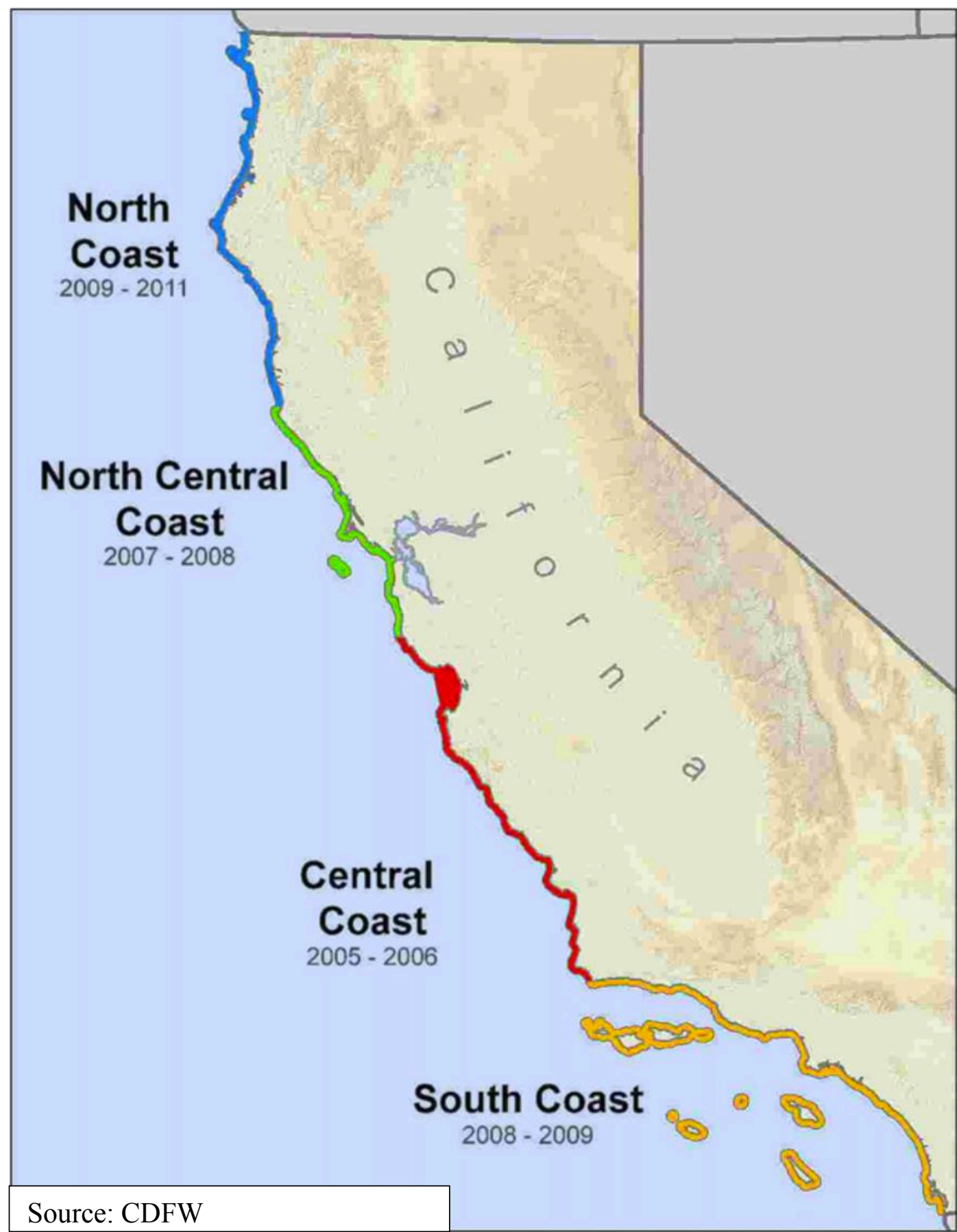


Appendix 2: LiMPETS Slide from Powerpoint shared with students about California's MPAs

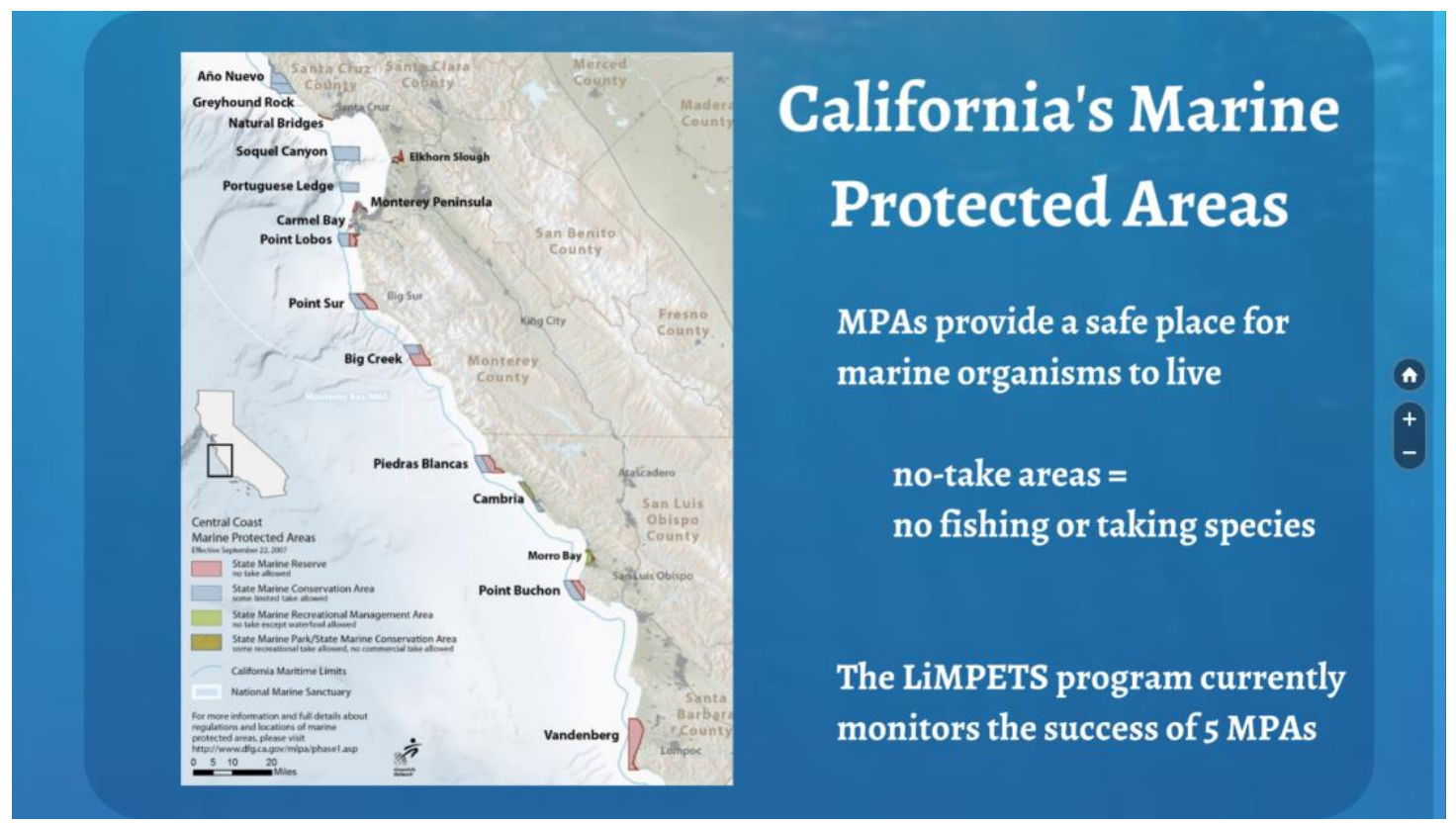

Source: shared with Author by interview subject 
Appendix 3: Tribal groups of California

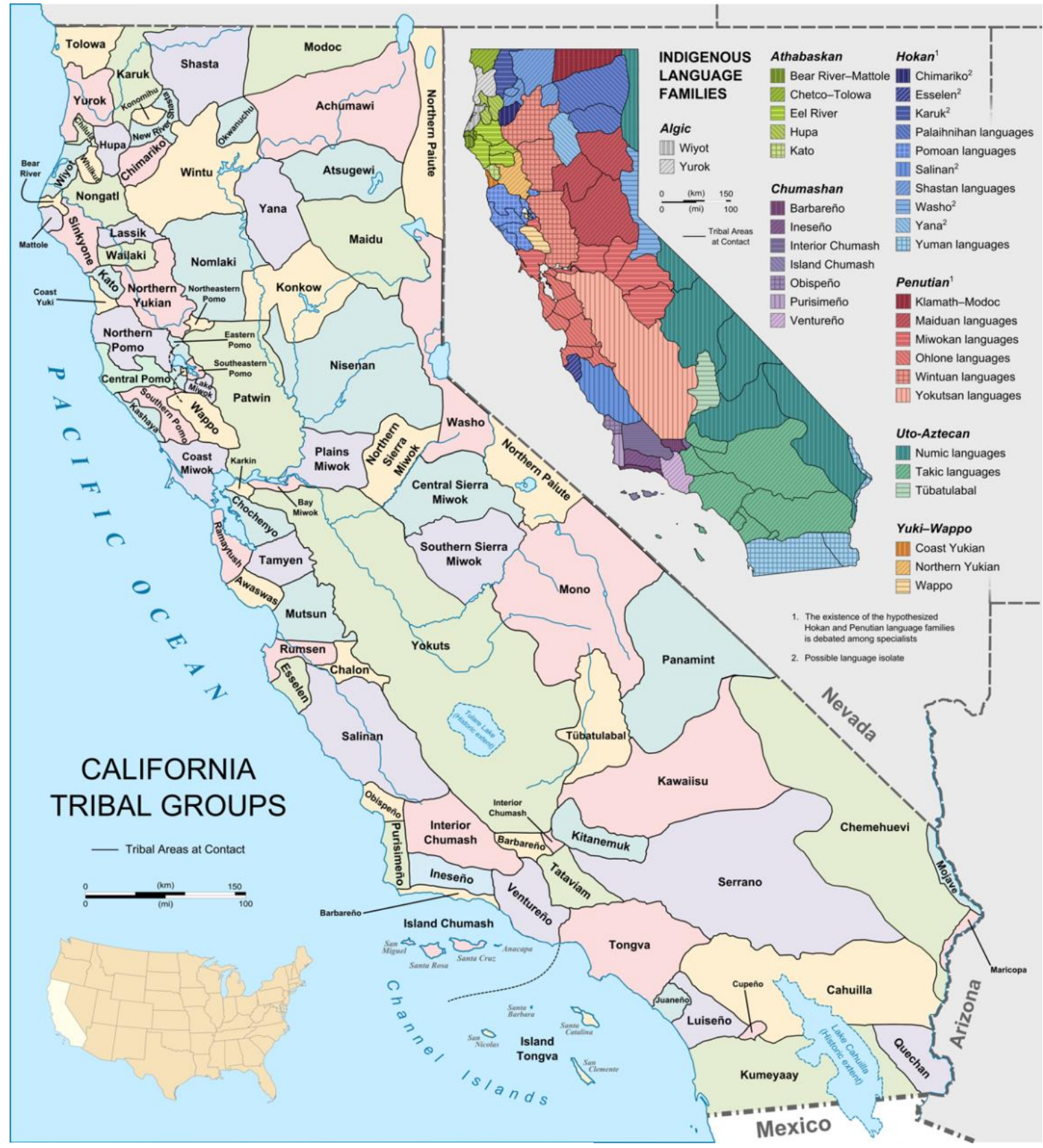

Source: University of California Berkeley 


\section{BIBLIOGRAPHY}

Aceves-Bueno, Eréndira, Adeyemi S. Adeleye, Darcy Bradley, W. Tyler Brandt, Patrick Callery, Marina Feraud, Kendra L. Garner,. 2015. "Citizen Science as an Approach for Overcoming Insufficient Monitoring and Inadequate Stakeholder Buy-in in Adaptive Management: Criteria and Evidence." Ecosystems 18 (3): 493-506.

Aswani, Shankar, Matthew Lauer. 2006. “Incorporating Fishermen's Local Knowledge and Behavior into Geographical Information Systems (GIS) for Designing Marine Protected Areas in Oceania." Human Organization 65 (1): 81-102.

Baird, Brian E., Amber J. Mace. 2006. "Regional Ocean Governance: A Look at California." Duke Environmental Law \& Policy Forum 12 (217): 217-226.

Barnard, A., and J. Spencer, eds. 2009. The Routledge Encyclopedia of Social and Cultural Anthropology. 2nd ed. London: Routledge.

Branchini, Simone, Francesco Pensa, Patrizia Neri, Bianca Maria Tonucci, Lisa Mattielli, Anna Collavo, Maria Elena Sillingardi, Corrado Piccinetti, Francesco Zaccanti, and Stefano Goffredo. 2015. "Using a Citizen Science Program to Monitor Coral Reef Biodiversity through Space and Time." Biodiversity and Conservation 24 (2): 319-36.

Bonney, Rick. Ballard, Heidi. Jordan, Rebecca. McCallie, Ellen. Phillips, Tina. Shirk, Jennifer. Wilderman, Candie C. 2009. "Public Participation in Scientific Research: Defining the Field and Assessing Its Potential for Informal Science Education. A CAISE Inquiry Group Report.” Online Submission.

California Department of Fish \& Game. 2008. "California Marine Live Protection Act Master Plan for Marine Protected Areas." https://www.dfg.ca.gov/marine/pdfs/revisedmp0108.pdf.

California Department of Fish and Wildlife, and California Ocean Protection Council. 2018. "Marine Protected Area Monitoring Program Action Plan." https://nrm.dfg.ca.gov/FileHandler.ashx?DocumentID=161748\&inline.

Carr, Mark H., Joseph E. Neigel, James A. Estes, Sandy Andelman, Robert R. Warner, John L. Largier. 2003. "Comparing marine and terrestrial ecosystems: implications for the design of coastal marine reserves." Ecological Applications 13 (1).

Carr, Mark H. Sarah P. Robinson, Charles Wahle, Gary Davis, Stephen Kroll, Samantha Murray, Ervin Joe Schumacker, Margaret Williams. 2017. "The Central importance of ecological spatial connectivity to effectice coastal 
marine protected areas and to meeting the challenges of climate change in the marine environment." Aquatic Conservation: Marine Freshwater Ecosystems 27(S1): 6-29.

California Ocean Protection Council. September 2018. "California MPA Education and Outreach Needs Assessment: Major Findings and Recommendations." Accessed March 2019. http://californiampas.org/mpaneedsassessment

Catlin-Groves, Christina L., 2012. "The Citizen Science Landscape: From Volunteers to Citizen Sensors and Beyond.” International Journal of Zoology: 1-15.

Cerrano, Carlo, Martina Milanese, Massimo Ponti, 2017. "Diving for Science -science for diving: volunteer scuba divers support science and conservation in the Mediterranean Sea." Aquatic Conservation: Marine and Freshwater Ecosystems 27: 303-323.

Chiang, Connie. 2008. Shaping the Shoreline: Fisheries and Tourism on the Monterey Coast. University of Washington Press.

Cigliano, John A, Meyer, Ryan. Ballard, Heidi L. Freitag, Amy. Phillips, Tina B. Wasser, Ann. 2015. "Making Marine and Coastal Citizen Science Matter." Ocean \& Coastal Management 115: 77-87.

Cigliano, John A. Ballard, Heidi L. (ed.) 2017. Citizen Science for Coastal and Marine Conservation. New York: Routledge.

Crabbe, M. James C. 2011. "From Citizen Science to Policy Development on the Coral Reefs of Jamaica.” International Journal of Zoology 2012: 1-6.

Cresswell, J.W., and Cresswell, J.D. 2017. Research Design: Qualitative, Quantitative, and Mixed Methods Approaches. 5th edition. Thousand Oaks: SAGE.

Dalton, T.M. 2005. "Beyond Biogeography: A Framework for Involving the Public in Planning of U.S. Marine Protected Areas.” Conservation Biology 19 (5): 1392 1401.

Dawson, Emily. 2014. “'Not Designed for Us”: How Science Museums and Science Centers Socially Exclude Low-Income, Minority Ethnic Groups." Science Education 98 (6): 981-1008.

Dawson, Emily. 2014. "Reframing Social Exclusion from Science Communication: Moving Away from 'barriers' towards a More Complex Perspective." SISSA Journal of Science Communication 13 (2): 1-4. http:/ 
Dawson, Emily. 2018. "Reimagining Publics and (Non) Participation: Exploring Exclusion from Science Communication through the Experiences of LowIncome, Minority Ethnic Groups." Public Understanding of Science 27 (7): $772-86$.

Dean, Angela J., Church, Emma K., Loder, Jenn., Fielding, Kelly S., and Wilson, Kerrie A. 2018. "How Do Marine and Coastal Citizen Science Experiences Foster Environmental Engagement?" Journal of Environmental Management 213 (May): 409-16. https://doi.org/10.1016/j.jenvman.2018.02.080.

Delaney, David G., Sperling, Corinne D., Adams, Christiaan S., Leung, Brian. 2008. "Marine Invasive Species: Validation of Citizen Science and Implications for National Monitoring Networks." Biological Invasions 10 (1): 117-28.

Dickinson, J.L, and R. Bonney, eds. 2012. Citizen Science: Public Participation in Environmental Research. Ithaca: Cornell University Press.

"Executive Order 13158: Marine Protected Areas." 2000. https://nmsmarineprotectedareas.blob.core.windows.net/marineprotectedareasprod/media/archive/pdf/eo/execordermpa.pdf.

Farm Bureau Monterey. "Monterey Agriculture.” Accessed February 2020. http://montereycfb.com/index.php?page $=$ overview

Freiwald, J., S. McMillan, Abbott, D., McHugh, K. Kozma. 2019. “Reef Check California Instruction Manual: A Guide to Monitoring California's Kelp Forests." Marina Del Ray, CA. https://reefcheck.org/PDFs/RCCAmanual9thedition.pdf.

Freiwald, Jan, Ryan Meyer, Jennifer E. Casselle, Carol A. Blanchette, Kevin Hovel, Doug Neilson, Jenifer Dugan, Jessica Altstatt, Kariana Nielsen, Julie Bursek. 2018. "Citizen science monitoring of marine protected areas: Case studies and recommendations for integration into monitoring programs." Marine Ecology 39: $1-11$.

Freitag, Amy. Pfeffer. Max J. 2013. "Process, Not Product: Investigating Recommendations for Improving Citizen Science “"Success."” PLOS ONE 8 (5).

Freitag, Amy, Ryan Meyer, and Liz Whiteman. 2016. "Strategies Employed by Citizen Science Programs to Increase the Credibility of Their Data." Citizen Science: Theory and Practice. 1 (1): 1-11. http://doi.org/10.5334/cstp.6

Fox, Evan, Melissa Miller-Henson, John Ugoretz, Mike Weber, Mary Gleason, John Kirlin, Meg Caldwell, Sonke Mastrup. 2013. "Enabling conditions to support 
marine protected area network planning: California's Marine Life Protection Act Initiative as a case study." Ocean \& Coastal Management 74: 14-23.

Gill, David A, Michael B. Mascia, Gabby N. Ahmadia, Louise Glew, Sarah E. Lester, Megan Barnes, Ian Craigie, Emily S. Darling, Christopher M. Free, Jonas Geldmann, Susie Holst, Olaf P. Jensen, Alan T. White, Xavier Basurto, Lauren Coad, Ruth D. Gates, Greg Guannel, Peter J. Mumby, Hannah Thomas, Sarah Whitmee, Stephen Woodley, Helen E. Fox. 2017. "Capacity shortfalls hinder the performance of marine protected areas globally." Nature 543: 665-679.

Gillet, David J., Daniel J. Pondella II, Jan Freiwald, Kenneth C. Schiff, Jennifer E. Caselle, Craig Schuman, Stephen B. Weisberg. 2012. "Comparing volunteer and professionaly collected monitoring data from the rocky subtidal reefs of Southern California, USA." Environmental Monitoring Assessment 184: 32393257.

Gleason, Mary, Scott McCreary, Melissa Miller-Henson, John Ugoretz, Evan Fox, Matt Merrifield, Will McClintock, Paulo Serpa, Kathryn Hoffman. 2010. "Science-based and stakeholder-driven marine protected area network planning: A successful case study from north central California." Ocean \& Coastal Management 53: 52-68.

Goffredo, Stefano, Francesco Pensa, Patrizia Neri, Antonio Orlandi, Maria Scola Gagliardi, Angela Velardi, Corrado Piccinetti, and Francesco Zaccanti. 2010. "Unite Research with What Citizens Do for Fun: Recreational Monitoring of Marine Biodiversity." Ecological Applications 20 (8): 2170-87.

Gurney, G.G.; J.E. Cinner, J. Sartin, R.L. Pressey, N.C. Ban, N.A. Marshall, D. Prabuning. 2016. "Participation in devolved commons management: Multiscale socioeceonomic factors related to individuals' participation in community-based management of marine protected areas in Indonesia." Environmental Science \& Policy 61: 212-220.

Helvey, Mark. 2004. "Seeking Consensus on Designing Marine Protected Areas: Keeping the Fishing Community Engaged." Coastal Management 32: 173-90.

Hermoso, Maria 1. Victoria Y. Martin, Wolfgang Stotz, Stefan Gelcich, Martin Thiel. 2019. "How Does the Diversity of Divers Affect the Design of Citizen Science Projects." Frontiers in Marine Science 6 (239): 1-15.

Hyder, Kieran, Bryony Townhill, Lucy G Anderson, Jane Delany, and John K Pinnegar. 2015. "Can Citizen Science Contribute to the Evidence-Base That Underpins Marine Policy?” Marine Policy 59: 112-20. 
International Union for the Conservation of Nature. "Marine Protected Areas." Updated 2019. Accessed February 2020. https://www.iucn.org/theme/marineand-polar/our-work/marine-protected-areas

Johnson, Jeffrey C., Daniel J. Hruschka, 2015 “Chapter 3: Research Design and Research Strategies." In Handbook of Methods in Cultural Anthropology. H. Russell Bernard, Clarence C. Gravlee. Rowman \& Littlefield. Second Edition: 97-130.

Jarvis, Rebecca M., Barbara Bollard Breen, Christian U. Krägeloh, D. Rex Billington. 2015. "Citizen Science and the power of public participation in marine spatial planning." Marine Policy 57: 21-26.

Jones, Benjamin L., Richard K.F. Unsworth, Len J. Mackenzie, Rudi L. Yoshida, Leanne C. Cullen-Unsworth. 2018. "Crowdsourcing conservation: The role of citizen science in securing a future for seagrass." Marine Pollution Bulletin 134: 210-215.

Kirlin, John, Meg Caldwell, Mary Gleason, Mike Weber, John Ugoretz, Evan Fox, Melissa Miller-Henson. 2013. "California's Marine Life Protection Act Initiative: Supporting implementation of legislation establishing a statewide network of marine protected area." Ocean \& Coastal Management 74: 3-13.

Laffoley, Dan, John M. Baxter, Jon C. Day, Lauren Wenzel, Paula Bueno, Katherine Zischka. "Chapter 29: Marine Protected Areas." In World Seas: An Environmental Evaluation Vol. III: Ecological Issues and Environmental Impacts. Ed. Charles Sheppard. Academic Publishers. 549-569.

Lauer, Matthew, and Shankar Aswani. 2009. "Indigenous Ecological Knowledge as Situated Practices: Understanding Fishers Knowledge in the Western Solomon Islands." American Anthropologist 111 (3): 317-29.

Lucrezi, Serena, Martina Milanese, Marco Palma, and Carlo Cerrano. 2018. "Stirring the Strategic Direction of Scuba Diving Marine Citizen Science: A Survey of Active and Potential Participants." PLoS ONE 13 (8): 1-45.

Mahajan, Shauna L, and Tim Daw. 2016. "Perceptions of Ecosystem Services and Benefits to Human Well-Being from Community-Based Marine Protected Areas in Kenya." Marine Policy 74: 108-119.

Malpica-Cruz, Luis, Laís C.T. Chaves, Isabelle M. Côté. 2016. "Managing marine invasive species through public participation: Lionfish derbies as a case study." Marine Policy 74: 158-164. 
Marshall, N Justin, Diana A Kleine, and Angela J Dean. 2012. "CoralWatch: Education, Monitoring, and Sustainability through Citizen Science." Frontiers in Ecology and the Environment 10 (6): 332-34.

Mascia, Michael. 2004. "Social Dimensions of Marine Reserves." In Marine Reserves : A Guide to Science, Design, and Use, edited by Jack A. Sobel and Craig P. Dahlgren, 379. Island Press.

Mascia, Michael, Claus, CA, Naidoo, R. 2010. "Impacts of marine protected areas on fishing communities." Conservation Biology 24 (5): 1424-1429.

Martin, Victoria. Smith, Liam. Bowling, Alison. Christidis, Les. Lloyd, David. Pecl, Gretta . 2016. "Citizens as Scientists: What Influences Public Contributions to Marine Research?” Science Communication 38 (4): 495-522.

McKinley, D. C., Miller-Rushing, A. J., Ballard, H., Bonney, R., Brown, H., Evans, D. M., Soukup, M. A. 2015. Investing in citizen science can improve natural resource management and environmental protection. Issues in Ecology 19: 127.

Mckinley, Duncan C, Abe J Miller-Rushing, Heidi L Ballard, Rick Bonney, Susan C Cook-Patton, Daniel M Evans, Rebecca A French. 2017. "Citizen Science Can Improve Conservation Science, Natural Resource Management, and Environmental Protection.” Biological Conservation 208: 15-28.

McNeill, Asha, Julian Clifton, and Euan S Harvey. 2018. "Attitudes to a Marine Protected Area Are Associated with Perceived Social Impacts.” Marine Policy 94: 106-118.

Meyer, Ryan, Erin Meyer, Leila Sievanen, Amy Freitag. 2017. "Using citizen science to inform ocean and coastal resource management." In Citizen Science for Coastal and Marine Conservation. John Ciglano and Heidi Ballard. Routledge.

Monterey Bay National Marine Sanctuary, NOAA. "Monterey Bay National Marine Sanctuary Overview." Updated December 9, 2019. Accessed February 2020. https://montereybay.noaa.gov/intro/welcome.html

Moore, Amelia. February 2018. Participant Observation Workshop.

National Marine Sanctuaries. "National Marine Sanctuary System: West Coast Region." Accessed February 2020. https://sanctuaries.noaa.gov/about/westcoast.html 
National Research Council (NRC). 2001. Marine Protected Areas: Tools for Sustaining Ocean Eco- systems. National Academy Press, Washington, DC.

Ordoñez-Gauger, Lucia, Laurie Richmond, Steven Hackett, Cheryl Chen. 2018. 'It's a trust thing: Assessing Fishermen's perceptions of the California North Coast marine protected area network." Ocean and Coastal Management 158: 144153.

Ottinger, Gwen. 2010. "Buckets of Resistance: Standards and the Effectiveness of Citizen Science." Science, Technology, and Human Values 35(2): 244-270.

Palumbi, Stephen R., Carolyn Sotka. 2011. The Death \& Life of Monterey Bay: A Story of Revival. Island Press.

Pandaya, Rajul E. 2012. "A framework for engaging diverse communities in citizen science in the US." Frontiers in Ecology and the Environment 10 (6): 314-317.

REEF CHECK FOUNDATION:: Reefcheck.org. Accessed April 27, 2019. https://reefcheck.org/california/training-schedule/.

Robson, Colin, McCartan, Kieran. 2016. Real World Research : A Resource for Users of Social Research Methods in Applied Settings. London: John Wiley \& Sons, Ltd.

Rosenblatt, Roger. October 5, 1998. "SYLVIA EARLE: Call of the Sea." Time Magazine. http://content.time.com/time/subscriber/article/0,33009,989255,00.html

Saarman, Emily T., Mark H. Carr. 2013. "The California Marine Life Protection Act: A balance of top down and bottom up governance in MPA Planning." Marine Policy 41: 41-49.

Schläppy, Marie-Lise, Jennifer Loder, Jodi Salmond, Alexandra Lea, Angela J. Dean, and Chris M. Roelfsema. 2017. "Making Waves: Marine Citizen Science for Impact." Frontiers in Marine Science 4: 146.

Silvertown, Jonathan. 2009. “A new dawn for citizen science.” Trends in Ecology and Evolution 24 (9): 467-471.

Stern, Marc. 2008. "Coercion, Voluntary Compliance and Protest: The Role of Trust and Legitimacy in Combating Local Opposition to Protected Areas." Environmental Conservation 35 (03).

Thiel, Martin, Miguel Penna Díaz, Guillermo Luna Jorquera, Sonia Salas, Javier Sellanes, and Wolfgang Stotz. 2014. "Citizen Scientists and Marine Research: 
Volunteer Participants, Their Contributions, and Projections for the Future." Oceanography and Marine Biology 52: 257-314.

Turrini, Tabea, Daniel Dörler, Anett Richter, Florian Heigl, Aletta Bonn. 2018. "The threefold potential of environmental citizen science - Generating knowledge, creating learning opportunities and enabling civic participation." Biological Conservation 225: 176-186.

Vann-Sander, Sarah, Julian Clifton, and Euan Harvey. 2016. "Can Citizen Science Work? Perceptions of the Role and Utility of Citizen Science in a Marine Policy and Management Context." Marine Policy 72: 82-93. https://doi.org/10.1016/j.marpol.2016.06.026.

United States Census Bureau. “Quick Facts: Monterey County.” Updated July 2019. Accessed February 2020. https://www.census.gov/quickfacts/montereycountycalifornia

United States Census Bureau. “Quick Facts: Santa Cruz County.” Updated July 2019. Accessed February 2020. https://www.census.gov/quickfacts/fact/table/santacruzcountycalifornia,monter eycountycalifornia/PST045219

United States Census Bureau. "Quick Facts: San Francisco County.” Updated July 2019. Accessed February 2020. https://www.census.gov/quickfacts/fact/table/sanfranciscocountycalifornia,san mateocountycalifornia,santacruzcountycalifornia,montereycountycalifornia/PS T045219

United States Census Bureau. “Quick Facts: San Mateo County.” Updated July 2019. Accessed February 2020.

https://www.census.gov/quickfacts/fact/table/sanmateocountycalifornia,santacr uzcountycalifornia,montereycountycalifornia/PST045219

United States Census Bureau. “Quick Facts: San Francisco County.” Updated July 2019. Accessed February 2020. https://www.census.gov/quickfacts/fact/table/sanfranciscocountycalifornia,san mateocountycalifornia,santacruzcountycalifornia,montereycountycalifornia/PS T045219

University of California Cooperative Extension. "Vegetable Research \& Information Center." Accessed February 2020. https://vric.ucdavis.edu/

Wandersman, Abraham. 2003. "Community Science: Bridging the Gap Between Science and Practice with Community-Centered Models." American Journal of Community Psychology 31 (3/4): 227-242. 
Wiggins, Sarah May. 2012. "Marine Protected Area Management: Diving to the Depths to Discover How Best Practice Is Achieved in California, New South Wales, and the Great Barrier Reef." https://www.wcmt.org 